1.

ANL-5123

Metallurgy and Ceramics

\author{
ARGONNE NATIONAL LABORATORY \\ P. O. Box 299 \\ Lemont, Illinois
}

\begin{abstract}
THE DEVELOPMENT OF EQUIPMENT AND METHODS FOR CENTRIEUGALLY CASTING REACTOR FUEL SLUGS
\end{abstract}

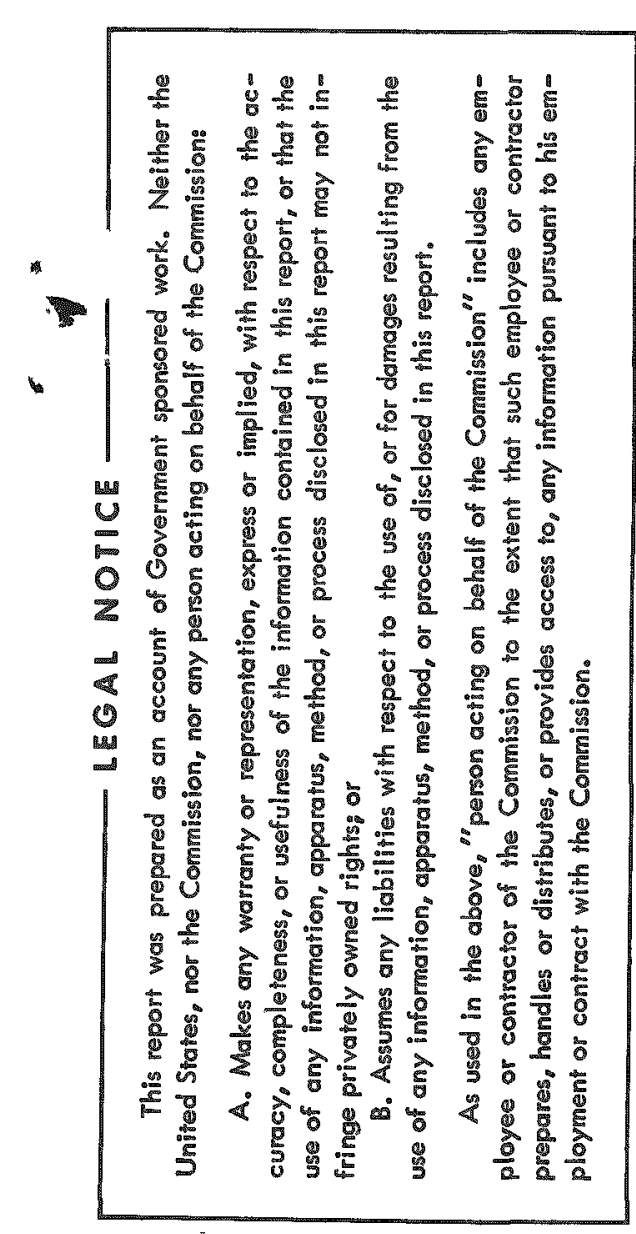

by

A. B. Shuck

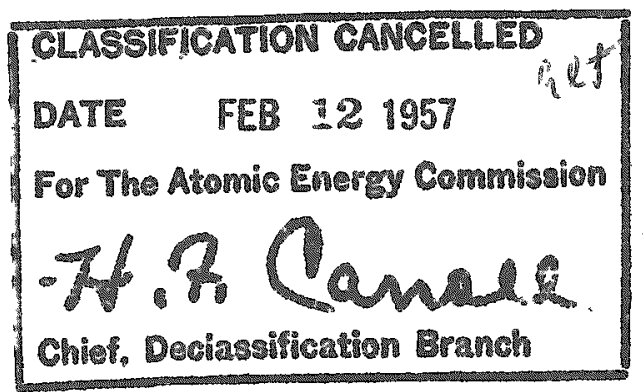

September 29,1953

METALLURGY DIVISION

Price $\$ 0.50$

Available from the

Office of Technical Services

Deparment of Commerce

Washington 25, D. C.

Operated by The University of Chicago

under

Contract $W-31-109-$ eng -38 


\section{DISCLAIMER}

This report was prepared as an account of work sponsored by an agency of the United States Government. Neither the United States Government nor any agency Thereof, nor any of their employees, makes any warranty, express or implied, or assumes any legal liability or responsibility for the accuracy, completeness, or usefulness of any information, apparatus, product, or process disclosed, or represents that its use would not infringe privately owned rights. Reference herein to any specific commercial product, process, or service by trade name, trademark, manufacturer, or otherwise does not necessarily constitute or imply its endorsement, recommendation, or favoring by the United States Government or any agency thereof. The views and opinions of authors expressed herein do not necessarily state or reflect those of the United States Government or any agency thereof. 


\section{DISCLAIMER}

Portions of this document may be illegible in electronic image products. Images are produced from the best available original document. 
TABLE OF CONTENTS

Page

ABSTRACT ..........................

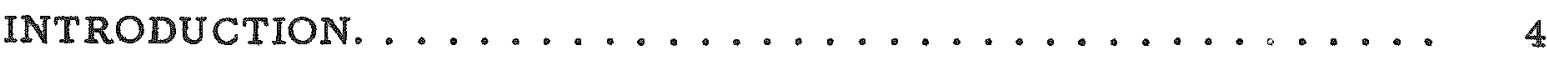

MULTIPLE MOLD CENTRIFUGAL CASTING ........... 7

DESIGN OF MACHINE. ..................... 7

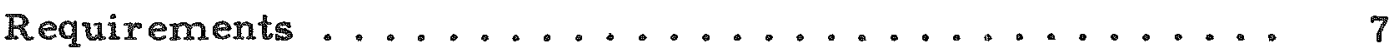

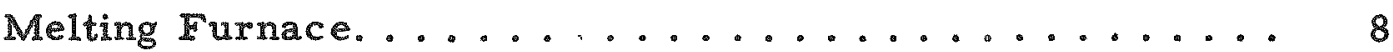

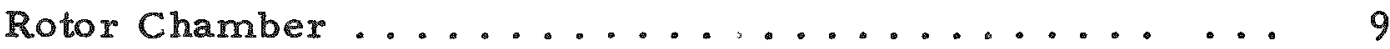

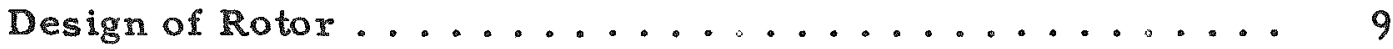

Spindle, Seals and Drive Mechanism ............ 14

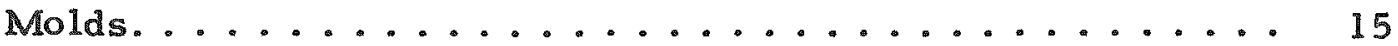

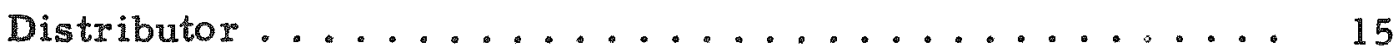

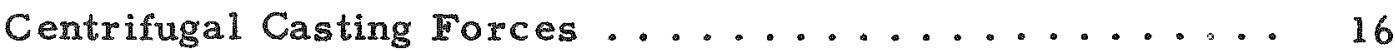

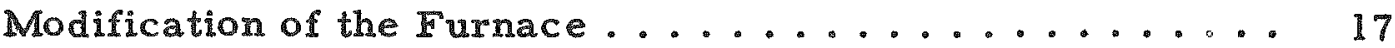

Vacuum Pumping System.................. 17

EXPERIMENTAL WORK .................. 17

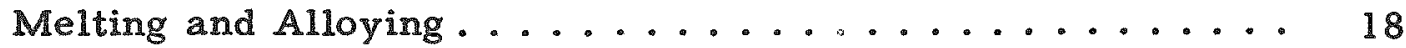

Rotor Assembly Modifications and Operations......... 21

Cooling, Furnace Disassembly and Casting Extraction .... 24

RECOMMENDED SEQUENCE OF OPERATIONS . . . . . . . . 24

Charge Preparation ...................... 24

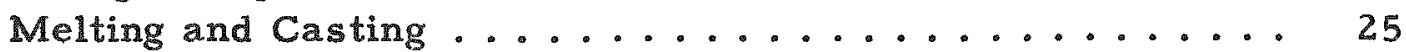

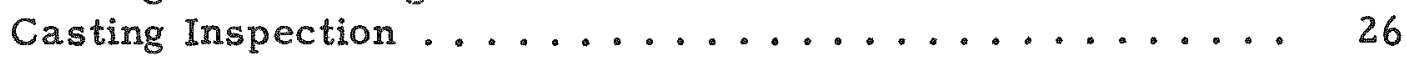

Parting Casting Tops and Machining ............ 26

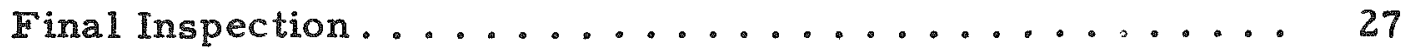

ENRICHED URANIUM-ZIRCONIUM ALLOY SLUGS . . . . . . . 28

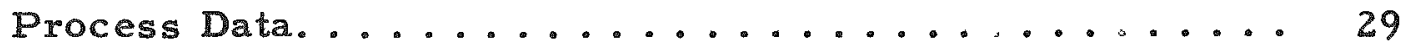

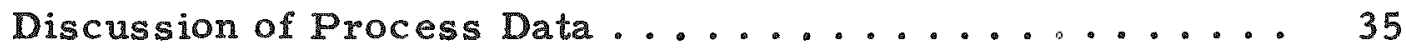

Thermal Cycling and Metallography of Centrifugally Cast

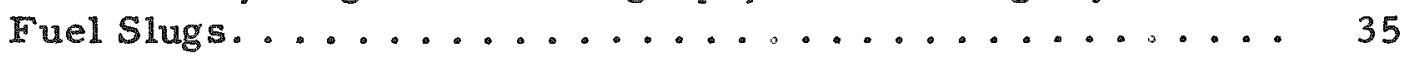

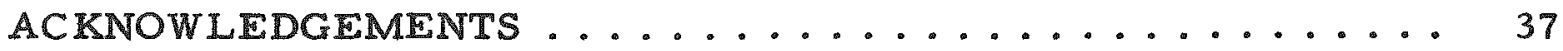

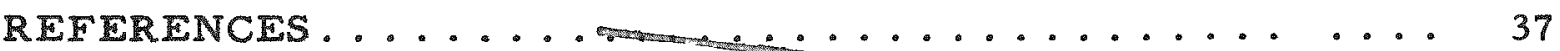

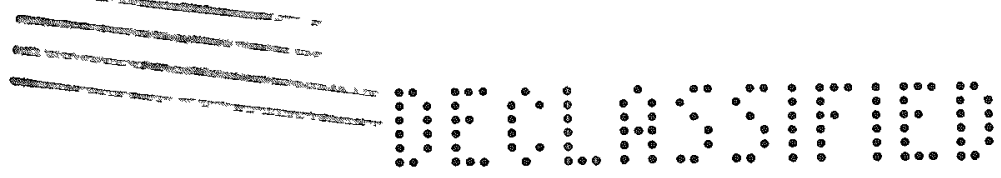




\title{
THE DEVELOPMENT OF EQUIPMENT AND METHODS FOR CENTRIFUGALLY CASTING REACTOR FUEL SLUGS
}

by

\author{
A. B. Shuck
}

\begin{abstract}
This report describes the design and construction of equipment and the development of methods for multiple mold, centrifugal casting of reactor fuel slugs. Advantages of the centrifugal casting method over the conventional fabrication methods were found to be (1) fewer operations, (2) fewer and more easily recovered residues, (3) less expensive equipment, and (4) the production of fuel slugs in shapes and in alloys not well adapted to other methods of manufacture. The method consisted of vacuum melting the alloy in stoppered crucrbles and bottom pouring into a spinning rotor carrying 16 radially arranged copper molds. The castings so produced were used without further processing, except for cropping the sprue end to obtain the specified length.

The method was found particularly adaptable to the production of enriched uranium-2w/o zirconium alloy fuel slugs for the Experimental Breeder Reactor (EBR). Theas cast surfaces were satisfactory for use in the NaK-bonded fuel rods, and the as-cast $2 \mathrm{w} / 0$ zirconium alloy slugs were found to be more dimensionally stable than slugs fabricated by conventional methods.
\end{abstract}

\section{INTRODUCTION}

The casting and fabrication of zirconium-stabilized uranium alloys has received considerable study since the first in-pile tests were made on the alloys over two years ago. Very briefly, the results of this study may be summarized as follows:

Melting and Casting:(1) By special melting techniques the high uranium-low zixconium alloys may be melted and cast with practically complete zirconium recovery. When poured into chill molds, the castings showed little segregation. The casting properties of the alloy, such as fluidity and mold reproduction, are excellent.

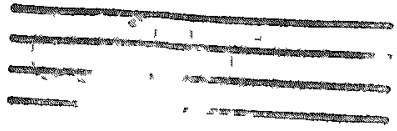


Fabrication: Difficulty was experienced in fabricating some of the first zirconium alloy samples. Further investigation revealed the following variation in workability of the alloy with zirconium content:

Table 1

WORKABILITY OF ZIRCONIUM - HIGH URANIUM ALLOYS

\begin{tabular}{|c|c|}
\hline $\begin{array}{l}w / 0 \\
Z x\end{array}$ & Fabricating Properties \\
\hline 0 & $\begin{array}{l}\text { Unalloyed uranium was rolled as much as } 90 \% \\
\text { reduction in area at } 300^{\circ} \mathrm{C} \text { without developing } \\
\text { stress cracks. }\end{array}$ \\
\hline 2 & $\begin{array}{l}\text { The alloy can be rolled to about } 40 \% \text { reduction in } \\
\text { area at } 300^{\circ} \mathrm{C} \text { from the as }- \text { cast condition. If, } \\
\text { however, after mild rolling the castings were } \\
\text { heated to } 800^{\circ} \mathrm{C} \text {, slow cooled to } 500^{\circ} \mathrm{C} \text {, and held } \\
\text { for two hours, they could be rolled more than } \\
65 \% \text { at } 300^{\circ} \mathrm{C} \text { without re-anneal. }\end{array}$ \\
\hline 4 & $\begin{array}{l}\text { The castings were rolled about } 25 \% \text { at } 300^{\circ} \mathrm{C} \text { be- } \\
\text { fore the appearance of stress cracks. The alloy } \\
\text { fabricated easily at } 600^{\circ} \mathrm{C} \text {. }\end{array}$ \\
\hline 6 & $\begin{array}{l}\text { The castings were fabricated without difficulty in } \\
\text { the high alpha temperature range. }\end{array}$ \\
\hline 10 & $\begin{array}{l}\text { Edge cracking was evident in iron-jacketed speci- } \\
\text { mens, flat rolled } 75 \% \text { at } 600^{\circ} \mathrm{C} \text {. }\end{array}$ \\
\hline 20 & $\begin{array}{l}\text { Iron-jacketed specimens, flat rolled } 75 \% \text { at } \\
600^{\circ} \mathrm{C} \text {, were badly broken up. }\end{array}$ \\
\hline
\end{tabular}

Heat Treatment:(1) The as-cast structure was fine grained. Thermal cycling tests indicated that no heat treatment, or at best, a simple stress relief, would be required to produce dimensional stability. The $2 \mathrm{w} / 0$ zirconium alloy, fabricated at $300^{\circ} \mathrm{C}$, showed the greatest stability when transformed from the gamma phase. However, when the specimens were quenched into water from $800^{\circ} \mathrm{C}$, the surfaces were badly oxidized and cracked. More favorable results were obtained if the specimens were bomb-cooled in air or if they were isothermally transformed by quenching into a $500^{\circ} \mathrm{C}$ bath. The as cast specimens were slightly more stable to thermal cycling than the $300^{\circ} \mathrm{C}$ fabricated and heat-treated specimens. 
Electrolytic Polishing: It is desirable to prepare the cylindrical surfaces of enriched uranium fuel slugs by electrolytic polishing rather than by machining. The electropolishing solutions used for unalloyed uranium did not remove the hard oxide produced by $800^{\circ} \mathrm{C}$ heat treatment of the uranium-zirconium alloy.

The foregoing observations, made while fabricating normal uranium and enriched uranium irradiation test specimens were born out in the fabrication of a series of full scale test fuel rods for irradiation in EBR. Individually cast fuel slugs in the as-cast condition and in the cast and alphaannealed condition were tested along with material rolled at $300^{\circ} \mathrm{C}$ and heat treated in various ways. The as-cast $2 \mathrm{w} / 0$ zirconium alloy showed greater dimensional stability to fast neutron irradiation than the fabricated and heat treated alloy. (2)

All of the tests indicated the need to develop a method of production of precise fuel slug castings. In addition it was desirable to simplify the manufacture of fuel slugs.

The original sequence of operations used to fabricate the unalloyed entiched EBR fuel slugs required 17 separateoperations, $(3,4)$ Adding 2 annealing operations for the conventional fabrication of $2 \mathrm{w} / 0$ zirconium alloy, a tota of 19 operations, each producing residue, would be required per batch of fuel fabricated. The casting residue and the machine turnings from the original fabrication were recovered by the Chemical Engineering Division at the Laboratory. These were fairly concentrated and rich residues. The residues from fabrication were much more lean and difficult to recover. These included high temperature heating oil and wiping cloths from the rolling and swaging operations, filter papers and filtrant from the heat treating and quenching operations, cleaning and drying solvents, electropolishing solutions, and miscellaneous residues such as cleaning tissues and pump oils. Manufacture of the fuel by a simple casting operation would eliminate most of the lean residues, which are difficult and expensive to recover.

The production of individual castings used in making the test fuel rods had 2 disadvantages: (1) only one casting was produced per melt, and (2) the density was 0.03 to $0.04 \mathrm{~g} / \mathrm{cc}$ less than that of the fabricated alloy. The individually cast slugs had excellent bright metallic surfaces which required no machining or electropolishing. Mold duplication was good. A diametral casting shrinkage of $2.8 \%$ seemed to be consistent enough to produce fuel slugs within the diameter specification. An individually cast fuel slug is shown in Figure 1. 


\section{MULTIPLE MOLD CENTRIFUGAL CASTING}

The 2 disadvantages of individual casting may be overcome by melting larger heats of metal, pouring several castings at a time, and by causing the metal to solidify under increased pressure. Multiple mold centrifugal casting was selected as the method to be investigated under this program.

Purpose of the Program

The objectives of the program were as follows: (1) to design and build a machine to produce fuel slugs of the EBR type by multiple mold centrifugal casting, (2) to test the centrifugal casting method of manufac turing fuel slugs, and (3) to study the characteristics and properties of the slugs produced. Secondary purposes of the program were (a) to reduce the number and complexity of operations required to produce $E B R$ fuel slugs, (b) to eliminate the more difficulty recovered residues, (c) to reduce the total quantity of enriched uranium in process, and (d) to provide methods of making fuel castings of alloys or in shapes which might not be easily fabricated by methods formerly employed.

\section{DESIGN OF MACHINE}

As originally conceived, the casting machine consisted of a melting furnace superimposed over a rotor assembly, allowing 2 to $3 \mathrm{~kg}$ of uranium alloy to be melted in a stoppered, bottom-pour crucible. After melting and outgassing, the metal would be poured into the rotor assembly as it rotated rapidly in the horizontal plane. The rotor assembly consisted of a central runner or distributor and a number of radially arranged chill molds. The entire assembly was enclosed and evacuated to a high vacuum, allowing the metal to be melted without oxidizing, to be outgassed, and allowed the use of high conductivity metal molds instead of a permeable mold material.

\section{$\underline{\text { Requirements }}$}

The following requirements were set for the design of the machine:

a. The furnace should melt sufficient metal to cast 16 fuel slugs weighing $150 \mathrm{~g}$ each, plus return scrap and residue.

b. A vacuum pumping system should be provided capable of evacuating the furnace and rotor housing to about $10^{-5} \mathrm{~mm}$ of $\mathrm{Hg}$ while melting, casting and cooling.

c. Provision should be made for preheating and outgassing the distributor runner and molds before pouring the melt. 
d. The metal should fill the molds and solidify under centrifugal force to promote high density and casting soundness.

e. To study the centrifugal effect provision should be made for speed variation and control.

f. The molds should be of high conductivity material (copper) which will resist the action of molten uranium alloy and cause the castings to solidify with a fine grained structure.

g. The rotor should be designed for safety at the highest operating speed of the machine.

h. The machine should be designed for convenience of operation and for complete recovery of the metal melted.

Figures 2 and 3 show the original design of the machine.

Melting Furnace

The melting furnace was of the tube type with an external induction heating coil. A 5-3/4" diameter by $27^{\prime \prime}$ long Vycor tube was used with pumping lines to both the upper and lower ends. The pumping lines were made from standard, 4 " diameter thin wall, stainless-steel welded pipe fittings. The upper and lower vacuum lines (Figure 2 , items 62 and 73 ) were joined to the vacuum header (Figure 2, item 72) by means of chevron sealed slip joints (Figure 2, item 71). The slip joints gave flexibility to the furnace, allowing furnace tubes of different lengths to be used, and made it possible to compensate for the crookedness of commercial Vycor and quartz tubing. In order to load the furnace and gain access to the rotor chamber, both sections may be swivelled out of the way without disassembling the vacuum system. Both sections were secured to the vacuum header by tie rods and a $180^{\circ}$ sector bracket. The principal advantage of the split pumping system was equalization of the vacuum in the upper and lower ends of the furnace.

The upper furnace vacuum line was capped by a furnace top containing the rubber gland for the water-cooled extension to the stopper rod and the sight window. Fogging of sight windows by evaporated metal coatings from the molten metal bath is always a problem in high vacuum melting furnaces. Two methods were used to overcome this difficulty. A shutter, operated through a second rubber gland, allowed the opening beneath the quartz window to be closed except while observations were underway. A $2-3 / 4$ " quartz disk was mounted eccentrically with respect to the $15 / 16^{\prime \prime}$ diameter opening in the furnace top. By rotating the quartz disk upon its Oring seal a number of clean sections could be exposed. 
The upper and lower ends of the furnace tube were sealed to the vacuum lines by means of silicone rubber gaskets set in water -cooled adapter rings. Furnace tubes of different diameter could be used by changing the adapter assemblies, allowing close coupled induction coils to be used with different sized furnace charges.

The vacuum header was connected to the high vacuum pumping system by a 6" pipe flange.

The inner furnace assembly consisted of a $5^{\prime \prime}$ O.D. $\times 4^{\prime \prime}$ I.D. $\times 13^{\prime \prime}$ long zirconia insulator tube lined with a $0.020^{\prime \prime}$ thick tantalum heater, a tapered MgO crucible pedestal, a standard V -2 crucible, stopper rod and cover of $\mathrm{MgO}$ or $\mathrm{ThO}_{2}$ and tantalum base and cover reflectors. This assembly was held within the furnace tube on a hollow nickel stool. The $\mathrm{V}-2$ crucibles had $7 / 16^{\prime \prime}$ pouring holes as received. In order to supply metal to the rotor more rapidly, these were enlarged to $7 / 8^{\prime \prime}$ diameter and $1-1 / 16^{\prime \prime}$ diameter stopper rods were substituted for the $5 / 8$ " diameter stoppers supplied with the $\mathrm{V}-2$ crucible assemblies. The nickel stool (Figure 2, item 75) extended down into the upper section of the distributor, forming a conduit through which the molten uranium alloy could be dropped, and prevented splatter.

\section{Rotor Chamber}

A chamber housing the rotor was located directly below the furnace assembly. This consisted of a standard $30^{\prime \prime}$ diameter dished and flanged stainless steel drum head. A hole was cut in the bottom of the bowl and a flange welded in place to allow bolting and O-ring gasketing to the frame of the machine. A 34" diameter stainless steel bolt ring was welded to the upper rim of the head. This was grooved for a $32^{\prime \prime}$ diameter O-ring. The rotor chamber was covered and connected to the furnace section by a $5 / 8$ " thick by 34" diameter cover plate. Bolts were placed in the rim of the cover and flange for locating purposes only, since when a vacuum was pumped on the chamber, the cover was clamped to the bowl by atmospheric pressure with a force of over five tons.

\section{Design of Rotor}

The mold and runner assembly was held in a forged steel rotor table shown in Figure 4. The rotor table with the original radial assembly of the molds and the copper distributor is shown in Figure 5. Since the forces and disruptive stresses in a rotating body vary as the square of the speed and since it is difficult to estimate shock loads, it is customary to provide a large stress safety factor in the design of such rotating machine elements as rotors and flywheels. The centrifugal casting machine rotor table was designed for a maximum speed of 2000 RPM and a minimum safety factor of 10 when carrying a full load of castings and molds. Stresses were calculated for speeds varying from 100 to 2000 RPM. A sample computation of the rotor stress at 1000 RPM using the configuration and dimensions shown in Figure 6 follows: 


\section{Calculation of Rotor Stresses}

(1) $F=2.842 \times 10^{-5} W_{R N^{2}}$

W - Weight in pounds

$\mathbf{R}$ - Radius of gyration

N - RPM

F - Force in pounds

(2) $R=\sqrt{\frac{I_{C}}{A}}$

$I_{C}$ - Axial moment of inertia

(3) $I_{c}=\Sigma I+\Sigma a d^{2}$

A - Area of Rotation

I - Moment of inertia of an element about any base

a - Cross sectional area of element

d - Distance from element base line to rotor axis

Area moment of inertia of rotor

(4) $\mathbb{I}_{c}=\frac{1.875 \times 1.5^{3}}{12}+1.875 \times 1.5 \times 1.75^{2}$

$$
\begin{aligned}
& +\frac{(1+1.875) 7.5}{2}\left[\frac{7.5(1.875+2)}{3(1.875+1)}+2.5\right]^{2} \\
& +7.5^{3} \frac{\left(1.875^{2}+4 \times 1.875+1\right)}{36(1.875+1)}+\frac{1.5^{4}}{12}+9.25^{2} \times 1.5^{2}
\end{aligned}
$$

(5) $I_{c}=622.5$ in."

Area of rotation, rotor

(6) $A=1.875 \times 1.5+\frac{2.875 \times 7.5}{2}+1.5^{2}=14.406$ sq. in.

Radius of gyration of rotor table, $\mathbb{R}$

$$
\text { (2a) } R=\sqrt{\frac{622.5}{14.4}}=6.574 \mathrm{in} \text {. }
$$

Weight of rotor, W

$$
\text { (7) W=2×3.1416 rAd } \quad \begin{aligned}
\text { A } & - \text { Area of rotation } \\
\mathbf{x} & - \text { Radius to centroid of rotated } \\
& \text { section } \\
\mathrm{d} & - \text { Density of steel, } 0.284 \mathrm{lb} / \mathrm{cu} \mathrm{in} .
\end{aligned}
$$


(8) Ar $=1.875+1.5 \times 175+\frac{2.875 \times 7.5}{2}\left[\frac{7.5(2+1.875)}{3(1+1.875)}+2.5\right]$ $+1.5^{2} \times 9.25$

$=80.58$ in. $^{3}$

(7a) $W=2 \times 3.1416 \times 80.58 \times 0.284$

$=144 \mathrm{lb}$.

Rotor centrifugal force at 1000 RPM

$$
\begin{aligned}
\text { (1a) } F & =2.8416 \times 10^{-5} \times 144 \times 6.574 \times 1000^{2} \\
F_{1000} & =26,900 \mathrm{lb} . \text { (due to rotor table alone) }
\end{aligned}
$$

W eight of copper mold

$$
\text { (9) } \mathrm{w}_{\mathrm{m}}=\mathrm{Vd} \quad \begin{aligned}
& \mathrm{W}_{\mathrm{m}}=\text { Weight of copper mold } \\
& \mathrm{v}=\text { Volume of molds } \\
& \mathrm{d}=\text { Density of copper } 0.324 \mathrm{lb} / \mathrm{cu} \mathrm{in} .
\end{aligned}
$$

From dimensions in Drawing No. MY $1498 \mathrm{D}-1$

$$
\text { (9a) } \begin{aligned}
W_{m}= & {\left[5.826 \times 1.5^{2}-0.219 \times 1.5 \times 1.25-4.5 \times 0.1875^{2} \times 3.1416\right.} \\
& \left.-\frac{0.5}{3}\left(0.1875^{2}+0.5^{2}+0.1875+0.5\right) 3.1614\right] 0.324 \\
= & 3.899 \mathrm{lb} . \text { per mold }
\end{aligned}
$$

(10) $16 \mathrm{~W}_{\mathrm{m}}=16 \times 3.899=62.3841 \mathrm{~b} \cdot \operatorname{per} 16 \mathrm{molds}$

Radius of gyration of molds using volume moment of inertia

$$
\text { (11) } R=\sqrt{\frac{I_{m v}}{V_{m}}} \quad \begin{aligned}
& I_{m v}=\text { Volume moment of inertia } \\
& V_{m}=\text { Volume of mold (copper) }
\end{aligned}
$$

Translation formula for volume moment of inertia of mold

(12) $I_{m v}=\Sigma I_{e v}+\Sigma V d^{3 / 3}$ 
Disregarding the small funnel at the mouth of the mold

$$
\begin{aligned}
& \text { (12a) } I_{\mathrm{mV}}=\frac{\left(5.826^{2}+1.5^{2}\right) 1.5^{2} \times 5.826}{12}+5.587^{2} \times 1.5^{2} \times 5.826 \\
& -\frac{0.197^{2} \times 3.1416 \times 5.076\left(0.197^{2}+5.076^{2 / 3}\right)}{4} \\
& -5.212^{2} \times 0.197^{2} \times 3.1416
\end{aligned}
$$

Radius of gyration of molds, $R_{m}$

$$
\text { (11a) } R_{m}=\sqrt{\frac{430.601}{12.489}}=5.872 \mathrm{in} \text {. }
$$

Centrifugal force per mold at 1000 RPM

$$
\text { (1 b) } \begin{aligned}
F_{m} & =2.8416 \times 10^{-5} \times 3.899 \times 5.872 \times 10^{6} \\
& =650.51 \mathrm{~b} .
\end{aligned}
$$$$
16 \mathrm{~F}_{\mathrm{m}}=10,408 \mathrm{lb} \text {. of centrifugal force, } 16 \mathrm{molds}
$$

Weight of casting, $W_{c}$

$$
\begin{aligned}
& \text { (13) } \mathrm{W}_{\mathrm{c}}=\mathbf{k V d} \\
& V=\text { Volume of casting } \\
& d=\text { Density of alloy, } 18.8 \mathrm{~g} / \mathrm{cc} \\
& k=\text { Conversion factor, } 16.39 / 453.6 \\
& \text { (13a) } W_{c}=\frac{0.192^{2} \times 3.1416 \times 5.076 \times 18.8 \times 16.39}{453.6} \\
& =0.399 \mathrm{lb} \text {. }
\end{aligned}
$$

Volume moment of inertia of casting, about rotor axis

$$
\text { (12c) } \begin{aligned}
I_{c V}= & \frac{0.192^{2} \times 3.1416 \times 5.076\left(0.192^{2}+5.076^{2 / 3}\right)}{4} \\
& +5.212^{2} \times 0.192^{2} \times 3.1416 \times 5.076 \\
= & 17.237 \mathrm{in.}^{5}
\end{aligned}
$$


Radius of gyration of castings, $R_{C}$

$$
\text { (11b) } \begin{aligned}
R_{c} & =\sqrt{\frac{17.237}{0.5872}} \\
& =5.418 \mathrm{in} .
\end{aligned}
$$

Centrifugal force per casting at 1000 RPM

$$
\text { (1c) } \begin{aligned}
F_{c} & =2.8416 \times 10^{-5} \times 0.399 \times 5.418 \times 10^{6} \\
& =61.41 \mathrm{~b} . \\
16 F_{c} & =982.41 \mathrm{~b} ., 16 \text { castings }
\end{aligned}
$$

Total centrifugal force on rotor

$$
\begin{aligned}
F_{t} & =F_{T}+F_{m}+F_{C} \\
& =26,900+10,408 \times 982 \\
& =38,2901 \mathrm{~b} .
\end{aligned}
$$

Computation of the stress distribution in a spinning wheel of nonuniform thickness and with varying external centrifugal loads becomes a complex problem. Graphic $(5)$ and semi-graphic $(6)$ computation methods are usually employed in solving these problems. An average disruptive stress, $S_{t a}$, in the rotor at 1000 RPM may be computed as follows:

$$
\begin{aligned}
S_{\mathrm{ta}} & =\frac{F_{t(1000)}}{3.1416 \times \mathrm{A}} \\
& =\frac{38,278}{3.1416 \times 14.4} \\
& =846 \text { psi avg. }
\end{aligned}
$$

Maximum tangential stress occurs at the bore of the wheel and in a disk of uniform cross section would be approximately 2 times the above figure. A more accurate estimate of the radial and tangential stresses in the rotor is given by a graphic computation by the method outlined by Robinson. (5) This is shown in Figure 7 and indicates a maximum tangential stress at the bore of 1400 psi at 1000 RPM. Because of the conical section, radial stress is almost uniform between the bore and the rim, i.e., between 700 and 670 psi at 1000 RPM. Both tangential and radial stresses fall off in the rim because of the increased cross section. 
Since centrifugal force is a function of the square of the rotor speed and since stress in the rotor varies as the centrifugal force, the following equations may be used to convert force and stress at 1000 RPM to that at any speed:

(16) $F_{\mathrm{n}}=F_{1000} \frac{\mathrm{n}^{2}}{10^{6}}$

$$
\begin{aligned}
F_{n} \text { and } S_{n}= & \text { Centrifugal force and } \\
& \text { stress at any speed, } \\
& \text { respectively } \\
n= & \text { RPM }
\end{aligned}
$$

(17) $s_{n}=s_{1000} \frac{n^{2}}{10^{6}}$

Assuming the tensile strength of the rotor steel to be 120,000 psi, it is possible to compute the bursting speed of the rotor, $n_{x}$ :

$$
\text { (17a) } \begin{aligned}
n_{r} & =\sqrt{\frac{120,000 \times 10^{6}}{1400}} \\
n_{x} & =\sqrt{85.7 \times 10^{6}} \\
n_{x} & =29,300 \mathrm{RPM}
\end{aligned}
$$

With a stress safety factor of 10 , the maximum operating speed, $n_{0}$, becomes

$$
\begin{aligned}
& \mathbf{n}_{0}=n_{r} / \sqrt{10} \\
& \mathbf{n}_{0}=9,300 \mathrm{RPM}
\end{aligned}
$$

This is far in excess of any speed contemplated for the machine.

Because of the tangential stress concentration at the bore of the rotor, there is a tendency for it to come loose from its shaft at comparatively low speeds. To overcome any loosening, the rotor was mounted on a 3-1/2" per foot tapered spindle nose. Any increase in the bore diameter caused the rotor merely to settle slightly on taper and did not disturb the alignment and balance of the rotor. A long draw bolt was provided to hold the rotor table elastically upon the taper for higher speed operation.

\section{Spindle, Seals and Drive Mechanism}

The spindle shaft was mounted in roller bearings in the frame of the machine. The rotor chamber was bolted onto the frame with an $O-r i n g$ seal between the lower flange of the chamber and the top of the frame. A double chevron seal (Item 26, Figure2) was used just above the upper roller bearing on the spindle as a running vacuum seal. The upper bearing was placed in a vacuum tight housing, and a second double chevron seal was used just below the bearing to act as a grease seal and an emergency vacuum seal. 
Ordinarily the bearing operated at air pressure, but provision was made to evacuate the bearing housing by a separate roughing pump in an emergency. The upper roller bearing was lubricated with vacuum grease.

Electric leads were brought in through the hollow shaft to the resistance heater used to outgas the molds and distributor.

The spindle was driven by a double V-belt transmission and a variable speed, direct current, 2 horsepower motor. A $4^{\prime \prime}$ diameter pulley on the motor and 6 " diameter pulley on the spindle produced a top speed of about 1150 RPM. A $6^{\prime \prime}$ motor pulley and $5^{\prime \prime}$ spindle pulley produced a top speed of 2000 RPM, but gave very sluggish acceleration. A magneto tachometer, belt driven from the spindle, gave a continuous indication of speed at the control panel. The drive control panel is shown in Figure 8 .

Molds

The mold construction is shown in Figure 4 , items 15 and 16 . The molds were machined from copper. After boring the cavities, a hardened steel pin was drawn through the mold cavities, burnishing the surfaces and bringing them to within a few ten thousandths of an inch of the specified size. The molds were balanced to within $1 / 2$ ounce.

Distributor

The melted alloy was dropped into a star shaped receiver, the pur pose of which was to distribute the metal equally into the molds in an even undisturbed flow. The first distributor was made of copper and consisted of a receiver basin surrounded by 16 small scoop shaped vanes and nozzles terminating in the mold funnels. The nozzles and the molds were arranged radially as shown in Figures 5 and 10 . This arrangement did not work. At high speeds, the metal pocketed in the scoops, and much of it froze in the distributor receiver as shown in Figure 9-a. The metal was delivered from the nozzles in a fine stream and was projected down the trailing side of the molds where it solidified and was pushed down into the mold cavities as a crumpled up mass. At lower speeds the metal solidified as a solid casting but showed severe turbulence and cavitation. Figure $9 \mathrm{mb}$ shows a heat of metal cast at 300 RPM.

After failure of the radial mold arrangement, a new distributor was designed according to centrifugal pump runner practice to streamline the flow of metal into the molds. The runners delivered metal to the molds at a lag angle of $30^{\circ}$ to the radial direction. The distributor was machined of graphite. Its dimensions are shown in Figure 11, and a photograph in Figure 12. A detailed analysis of the design is given under the section Experimental Work. 
The arrangement of the copper molds around the distributor is shown in Figures 13 and 14. They were clamped down to the rotor table by means of finger clamps and a single bolt through one corner of each mold. They were wedged against the outer rim of the table and against one another. The axial lines of the molds formed $35^{\circ}$ angles with radii drawn through the center of the mold funnels. The rotor assembly with the graphite distributor and angled molds is shown in Figure 15. This distributor and mold arrangement could be made to produce satisfactory castings when operated at speeds of between 300 and 500 RPM.

\section{Centrifugal Casting Forces}

A convenient expression for the force acting at any point on the molten metal within the molds is in terms of multiples of the force of gravity, cus tomarily termed G-factors, or simply G's. These may be computed from the following relationship:

$$
\begin{aligned}
F=3.833 \times 10^{-3} \mathrm{rn}^{2} \quad & F=\text { Force in } G^{\prime} s \\
& r=\text { Radius in inches } \\
& n=\text { Speed in RPM }
\end{aligned}
$$

Measurement of the rotor assembly gave radii of $7.625^{\prime \prime}$ and $3.375^{\prime \prime}$ for the "bottom" and "top" of a 4-1/4" fuel slug with the radial assembly, and 8.000 and $3.750^{\prime \prime}$ for the "bottom" and "top" of the fuel slug in the $35^{\circ}$ angled assembly. Table II shows the centrifugal force in $G^{\prime}$ s for various rotor

\begin{tabular}{|c|c|c|c|c|c|c|c|c|c|}
\hline \multirow{2}{*}{$\mathrm{n}$} & \multicolumn{2}{|c|}{ Radial Molds } & \multicolumn{2}{|c|}{$35^{\circ}$ Angled } & \multirow{2}{*}{$\begin{array}{c}\mathbf{n} \\
\text { RPH }\end{array}$} & \multicolumn{2}{|c|}{ Radial Molds } & \multicolumn{2}{|c|}{$35^{\circ}$ Angled } \\
\hline & $7.625^{\pi}$ & $3.375^{11}$ & $8.000^{n}$ & $3.750^{n}$ & & $7.625^{\circ}$ & $3.375^{11}$ & $8.000^{n} \mathrm{I}$ & $3.750^{\circ} \mathrm{I}$ \\
\hline 100 & 2.92 & 1.30 & 3.07 & 1.84 & 900 & 236.7 & 104.5 & 248.6 & 116.6 \\
\hline 150 & 6.58 & 2.90 & 6.90 & 3.23 & 1000 & 292.3 & 129.4 & 306.6 & 143.7 \\
\hline 200 & 11.69 & 5.16 & 12.27 & 5.75 & 1100 & 353.6 & 156.2 & 371.0 & 173.9 \\
\hline 250 & 18.27 & 8.02 & 19.17 & 8.98 & 1200 & 420.9 & 185.9 & 441.6 & 207.9 \\
\hline 300 & 26.30 & 11.62 & 27.60 & 12.94 & 1300 & 493.9 & 218.1 & 518.2 & 242.9 \\
\hline 350 & 35.80 & 15.81 & 37.56 & 17.61 & 1400 & 572.8 & 253.0 & 601.0 & 281.7 \\
\hline 400 & 46.76 & 20.65 & 49.06 & 23.00 & 1500 & 657.6 & 290.4 & 689.9 & 323.4 \\
\hline 450 & 59.18 & 26.14 & 62.10 & 29.11 & 1600 & 748.2 & 330.4 & 785.0 & 368.0 \\
\hline 500 & 73.07 & 32.27 & 76.66 & 35.93 & 1700 & 844.6 & 373.0 & 886.2 & 415.4 \\
\hline 600 & 105.2 & 46.46 & 110.4 & 51.75 & 1800 & 946.9 & 418.2 & 993.5 & 465.7 \\
\hline 700 & 143.2 & 63.24 & 150.3 & 70.43 & 1900 & 1055.1 & 465.9 & 1107.0 & 518.9 \\
\hline 800 & 187.1 & 82.60 & 196.3 & 91.99 & 2000 & 1169.1 & 516.3 & 1226.6 & 575.0 \\
\hline
\end{tabular}
speeds.

\section{Table II}

CALCULATED CENTRIFUGAL FORCE IN G FACTORS VERSUS ROTOR SPEED

These figures are plotted in Figures 16 and 17. 


\section{Modification of the Furnace}

Tests of the furnace in its original form showed the need of modification. The 18" drop from the crucible bottom to the distributor caused the metal striking the distributor to splatter into the bottom of the molds in the form of small shot which were not remelted when the main flow of metal arrived at the mold. To correct this, the furnace was rebuilt, lowering the melting zone about $13^{\prime \prime}$ by eliminating the T-section on the lower vacuum line. The lower furnace tube adapter $r$ ing and stool were bolted and gasketed directly to the rotor chamber cover. The stool was shortened to about $5-1 / 2^{\prime \prime}$, allowing the whole furnace assembly to be lowered to within about $5^{\prime \prime}$ of the top of the rotor. The $L$ shaped lower vacuum line was replaced by a straight section with a flange on the end which bolted directly to the rotor chamber cover. These modifications are shown in Figures 13 and 18.

\section{Vacuum Pumping System}

The centrifugal casting machine was evacuated by a portable $6^{\prime \prime}$ pumping system manufactured by Distillation Products, Inc. The system, starting at the casting machine, consisted of a $6^{\prime \prime}$ valve and $2^{\prime \prime}$ roughing bypass line which bolted directly to the furnace flange, a $6^{\prime \prime}$ oil diffusion pump, a $4^{\prime \prime}$ oil booster pump, and 2 mechanical roughing pumps. The roughing pumps were connected and valved in such a manner that one could be used to hold the vacuum on the pumps while the large main valve was closed and the centrifugal casting machine was open. After closing and sealing the centrifugal casting machine, the second mechanical pump was used to pump the machine down to 50 microns of $\mathrm{Hg}$ before the main valve was opened to the diffusion pumps. The second roughing pump was then switched in parallel with the first roughing pump to give an increased capacity to the mechanical pump section. Evacuation of the casting machine required between 10 and $15 \mathrm{~min}$. With the cold trap provided with the original furnace assembly, the furnace pumped down to an ultimate vacuum of between $10^{-6}$ and $10^{-5} \mathrm{~mm}$ of $\mathrm{Hg}$. Without the cold trap as in the final furnace assembly the ultimate vacuum was about $2 \times 10^{-5} \mathrm{~mm}$ of $\mathrm{Hg}$. In operation a vacuum of less than $4 \times 10^{-4} \mathrm{~mm}$ of $\mathrm{Hg}$ was found to give satisfactory results. Provision of a cold trap in the upper furnace line would require only slight modification of the furnace and should be made.

The reverse side of the casting machine, the motor mount, and method of attachment of the pumping system are shown in Figure 19.

\section{EXPERIMENTAL WORK}

Upon receipt of the machine from the Central Shops Division, it was assembled for test in the area of Building 16. Leaks were located by means of a helium leak detector, and the leaks were sealed. The rotor was 
operated at about $500 \mathrm{RPM}$ for 5 hours to test the leak characteristics of the Apiezon lubricated chevron seals. The seals were vacuum tight, but ran hot. The condrtion was corrected by boring the brass retaining ring about $0.030^{\prime \prime}$ larger than specified. A small quantity of molybdenum sulfide was added to the vacuum grease to improve its lubricating properties. After an original break-in period, the chevron seals performed satisfactorily.

The machine operated without noticeable vibration, except for a low amplitude critical at 940 RPM. The vibration at this speed was not sufficient to disturb the metal in the crucible or to interfere with the operation of the machine.

\section{Normal Uranium Alloy Test Melts}

A series of 17 test heats were melted using normal uranium and crystal bar zirconium to establish the conditions necessary to produce satisfactory fuel slugs. The following factors were found to influence the quality of the castings:

a. Melting and Alloying

1. Quantity of alloy melted

2. Method of alloy addition

3. Crucible material

4. Pouring temperature

5. Pouring rate

6. Vacuum

b. Centrifugal Casting

1. Distributor design

2. Direction of delivery of metal to molds

3. Lag angle of molds

4. Rotor speed

5. Degree of preheating and outgassing of distributor and molds

There was insufficient time to test each of the variables independently and in combination, and changes were made to suit the conditions as they were observed. Table III shows the results obtained in the tests. These are further explained below.

\section{Melting and Alloying}

Quantity of Alloy Melted

It was found that approximately $3100 \mathrm{~g}$ of $2.15 \mathrm{w} / 0$ zirconiumuranium alloy were needed to fill the molds and the small pouring funnel at the mold opening. When the pouring funnel was filled, no shrinkages 


\begin{tabular}{|c|c|c|c|c|c|c|c|c|c|c|c|}
\hline $\begin{array}{l}\text { Melt } \\
\text { No. }\end{array}$ & $\begin{array}{r}\text { Quant } \\
\text { A1loy, }\end{array}$ & Gry of & Distributor & $\begin{array}{l}\text { Mold } \\
\text { Arrangement } \\
\end{array}$ & $\begin{array}{l}\text { Rotor } \\
\text { Hester }\end{array}$ & Crucible & $\begin{array}{l}\text { Pour } \\
\text { Hole }\end{array}$ & $\begin{array}{l}\text { Pour } \\
\text { Tenw. }\end{array}$ & $\begin{array}{l}\text { Vacian, } \\
\operatorname{man} \text { of } \mathrm{Hg}\end{array}$ & $\begin{array}{l}\text { RPM. } \\
\text { Rotor } \\
\text { Speed }\end{array}$ & Results \\
\hline 1 & $\begin{array}{l}\mathbf{Z}_{\mathbf{r}} \\
\mathbf{v}\end{array}$ & $\begin{array}{r}49.441 \\
2257.610 \\
\end{array}$ & $\begin{array}{l}\mathrm{Cu} \\
\mathrm{Cu}\end{array}$ & Radial & none & $\mathrm{ThO}_{2}$ & $7 / 16^{\prime \prime}$ & $1450^{\circ} \mathrm{C}$ & $\begin{array}{l}2.5 \times 10^{-6} \\
5.4 \times 10^{-5}\end{array}$ & 800 & The stupper rod failed; no casting was produced. \\
\hline 2 & $\mathbb{Z}_{\mathbf{r}}$ & $\begin{array}{r}49.940 \\
2252.041\end{array}$ & $\mathrm{Cu}$ & Randial & none & $\mathrm{ThO}_{2}$ & $7 / 16^{\mathrm{a}}$ & $1450^{\circ} \mathrm{C}$ & $\begin{array}{l}1.5 \times 10^{-5} \\
1.4 \times 10^{-4}\end{array}$ & 800 & $\begin{array}{l}\text { Most of the tal remained behind in the distributor; } \\
\text { easting poor. }\end{array}$ \\
\hline 3 & $\begin{array}{l}\mathrm{Z}_{\mathbf{r}} \\
\mathrm{U}\end{array}$ & $\begin{array}{r}49.481 \\
2251.041\end{array}$ & $\mathrm{Cu}$ & Radial & none & $\mathrm{ThO}_{3}$ & $7 / 16^{8}$ & $1450^{\circ} \mathrm{C}$ & $\begin{array}{l}2.6 \times 10^{-5} \\
8.0 \times 10^{-5}\end{array}$ & 800 & $\begin{array}{l}\text { The distributor channels were enlarged to } 3 / 8^{m} \text {. Wore } \\
\text { of the metal went into the molds. but the castings } \\
\text { were a mass of shredded metal. }\end{array}$ \\
\hline 4 & 2. & $\begin{array}{l}\text { Reme l ted } \\
2239.126\end{array}$ & $\mathrm{Cu}$ & Radial & none & $\mathrm{THO}_{2}$ & $7 / 16^{m}$ & $1500^{\circ} \mathrm{C}$ & $\begin{array}{l}2.5 \times 10^{-5} \\
3.9 \times 10^{-4}\end{array}$ & 600 & $\begin{array}{l}\text { The castings were improved over those of previous ane } 1 \text { ts. } \\
\text { Graphite coated molds were not helpful. The surfaces } \\
\text { showed laps. }\end{array}$ \\
\hline 5 & 3. & $\begin{array}{l}\text { Reme } 1 \text { ted } \\
2228.148\end{array}$ & $\mathrm{Cu}$ & Radial & none & $\mathrm{ThO}_{2}$ & $7 / 16^{n}$ & $1500^{\circ} \mathrm{C}$ & $\begin{array}{l}1.4 \times 10^{-5} \\
9.0 \times 10^{-5}\end{array}$ & $\begin{array}{l}500 \\
900\end{array}$ & $\begin{array}{l}\text { The stopper rod was lifted } 500 \text { RHA while the rotor } \\
\text { accelerated to } 900 \text { RRM. Castings were solid, but each } \\
\text { casting showed seven layers. }\end{array}$ \\
\hline 6 & $\begin{array}{l}\mathbb{Z}_{x} \\
U\end{array}$ & $\begin{array}{r}49.595 \\
2257.128\end{array}$ & Cas & Radial & none & $\mathrm{ThO}_{2}$ & $7 / 16^{n}$ & $1500^{\circ} \mathrm{C}$ & $\begin{array}{l}3.0 \times 10^{-5} \\
7.6 \times 10^{-5}\end{array}$ & 500 & The castings were similar to those from melt 4 , not good. \\
\hline 7 & $\begin{array}{l}Z_{\text {T }} \\
\mathrm{u}\end{array}$ & $\begin{array}{r}47.120 \\
2145.128 \\
\end{array}$ & $\mathrm{Cu}$ & Radial & none & $\mathrm{ThO}_{2}$ & $7 / 16^{\mathrm{n}}$ & $1500^{\circ} \mathrm{C}$ & $\begin{array}{l}3.0 \times 10^{-5} \\
8.2 \times 10^{-5} \\
\end{array}$ & $\cdots$ & The nelt was not poured. The crucible used 6 times, broke. \\
\hline 8 & $5+7$ & $\begin{array}{l}\text { Rene l ted } \\
2345.523\end{array}$ & $\mathrm{Cu}$ & Radial & none & $\mathrm{ThO}_{2}$ & $5 / 8^{n}$ & $1500^{\circ} \mathrm{C}$ & $\begin{array}{l}2.8 \times 10^{-5} \\
1.4 \times 10^{-4}\end{array}$ & 500 & $\begin{array}{l}\text { The molds were filled better, probably because of the an- } \\
\text { larged hole. Eight molds had graphite coating; surfaces } \\
\text { were poor on these. }\end{array}$ \\
\hline 9 & $6+4$ & $\begin{array}{l}\text { Rene } 1 \text { ted } \\
2438.211\end{array}$ & $\mathrm{Cu}$ & Radial & $\begin{array}{c}5-8 \mathrm{amp} \\
1-3 / 4 \mathrm{hr}\end{array}$ & $\mathrm{ThO}_{2}$ & $5 / 8^{n}$ & $1525^{\circ} \mathrm{C}$ & $\begin{array}{l}3.2 \times 10^{-5} \\
1.8 \times 10^{-4}\end{array}$ & $\begin{array}{l}450 \\
800\end{array}$ & $\begin{array}{l}\text { Accelerating pour technique used, the distributor heated } \\
\text { to about } 300^{\circ} \mathrm{C} \text {; molds, } 100^{\circ} \mathrm{CH} \text {. The surfaces were mueh } \\
\text { improved, but still showed laps. }\end{array}$ \\
\hline 10 & 9. & $\begin{array}{l}\text { Remel ted } \\
2386.321\end{array}$ & Graphite & $35^{\circ}$ & $\begin{array}{c}5-8 \text { amp } \\
1-3 / 4 \mathrm{hr}\end{array}$ & $\mathrm{ThO}_{2}$ & $5 / 8^{n}$ & $1500^{\circ} \mathrm{C}$ & $\begin{array}{l}3.2 \times 10^{-5} \\
1.4 \times 10^{-4}\end{array}$ & 500 & $\begin{array}{l}\text { Crucible stuck to stopper rod, was picked up, and then } \\
\text { broken. Surprisingly, the castings were excellent al- } \\
\text { though distributor was ruined. }\end{array}$ \\
\hline 11 & $4+7$ & $\begin{array}{l}\text { Remel ted } \\
2723.845\end{array}$ & Græphi te & $35^{\circ}$ & $\begin{array}{l}5.8 \text { amp } \\
1-3 / 4 \mathrm{hr}\end{array}$ & $\mathrm{ThO}_{2}$ & $8 / 8^{n}$ & $1500^{\circ} \mathrm{C}$ & $\begin{array}{l}1.0 \times 10^{-4} \\
4.5 \times 10^{-5}\end{array}$ & 375 & $\begin{array}{l}\text { The castings looked good, but gome had laps. Elevens } \\
\text { cast ings were nearly perfect. Five were probably not } \\
\text { acceptable. }\end{array}$ \\
\hline 12 & $\begin{array}{l}\mathbf{Z}_{\mathbf{r}} \\
\mathrm{u}\end{array}$ & $\begin{array}{r}56.823 \\
2592.168\end{array}$ & Graphi te & $35^{\circ}$ & $\begin{array}{l}5-8 \text { amp } \\
2-1 / 4 \mathrm{hr}\end{array}$ & $\mathrm{THO}_{2}$ & $7 / 8^{\prime \prime}$ & $1500^{\circ} \mathrm{C}$ & $\begin{array}{l}9.2 \times 10^{-5} \\
4.0 \times 10^{-4}\end{array}$ & $\begin{array}{l}375 \\
600\end{array}$ & $\begin{array}{l}\text { Accelerating pour technique was used. The castings were } \\
\text { somewhat better than those of melt } 111 \text {. Fourteen of } \\
\text { sixteen were good. }\end{array}$ \\
\hline 13 & $\mathrm{Zr}$ & $\begin{array}{r}57.823 \\
2611.856 \\
\end{array}$ & Graphi te & $35^{\circ}$ & $5.8 \operatorname{mp}$ & $\mathrm{ThO}_{2}$ & $7 / 8^{n}$ & $1375^{\circ} \mathrm{C}$ & $\begin{array}{l}1.0 \times 10^{-8} \\
8.0 \times 10^{-3}\end{array}$ & $\cdots$ & Crucible broke the first time used; no castings. \\
\hline 14 & $4+8+1$ & $\begin{array}{l}\text { Reme } 1 \text { ted } \\
2611.982\end{array}$ & Graphi te & $35^{\circ}$ & 5-8 angs & $\mathrm{ThO}_{2}$ & $7 / 8^{n}$ & $1420^{\circ} \mathrm{C}$ & $\begin{array}{l}1.1 \times 10^{-4} \\
2.5 \times 10^{-4}\end{array}$ & $\cdots$ & $\begin{array}{l}\text { Crucible broke; no castings were produced. Need a more } \\
\text { reliable crucible. }\end{array}$ \\
\hline 15 & 12. & $\begin{array}{l}\text { Reane } 1 \text { ted } \\
2484.372\end{array}$ & Graphì te & $35^{\circ}$ & $5-8 \operatorname{arsp}$ & mso & $7 / 8^{n}$ & $1425^{\circ} \mathrm{C}$ & $\begin{array}{l}9.0 \times 10^{-5} \\
3.5 \times 10^{-4}\end{array}$ & 300 & $\begin{array}{l}\text { The casting sturfaces looked good, but molds were not well } \\
\text { filled. Rotor speed was too slow. Hgo crucible was not } \\
\text { bedly eroded. }\end{array}$ \\
\hline 16 & $\begin{array}{l}14 . \\
Z_{r} \\
\mathfrak{v}\end{array}$ & $\begin{array}{r}2244.057 \\
16.659 \\
75 \% .099\end{array}$ & Graphi te & $35^{\circ}$ & $5-8 \operatorname{argp}$ & $\mathrm{MgO}$ & $7 / 8^{n}$ & $1425^{\circ} \mathrm{C}$ & $\begin{array}{l}8.5 \times 10^{-5} \\
2.0 \times 10^{-4}\end{array}$ & $\begin{array}{l}400 \\
600\end{array}$ & $\begin{array}{l}\text { The castings showed slight flow marks on the surfaces, } \\
\text { but were well formed and filled. All sisteen would be } \\
\text { acceptable. }\end{array}$ \\
\hline 17 & $\begin{array}{l}2 \pi \\
v\end{array}$ & $\begin{array}{r}64.895 \\
2952.987\end{array}$ & Graphi te & $35^{\circ}$ & $5-8 \operatorname{arp}$ & $M g O$ & $7 / 8^{n}$ & $\begin{array}{l}1425^{\circ} \mathrm{C} \\
1400^{\circ} \mathrm{C}\end{array}$ & $\begin{array}{l}1.1 \times 10^{-4} \\
3.4 \times 10^{-5}\end{array}$ & $\begin{array}{l}375 \\
600\end{array}$ & $\begin{array}{l}\text { The casting surfaces were not quite as smooth or as bright } \\
\text { as those of melt } 16 \text {, but were considered acceptable. }\end{array}$ \\
\hline
\end{tabular}


were observed within the castings. When the funnels were not filled, a shrinkage depression formed at the sprue end of the casting. This could be traced within the casting as a discontinuous centerline porosity to a considerable depth. Of the $3100 \mathrm{~g}$ of alloy melted, approximately $2400 \mathrm{~g}$ were required for the 16 finished fuel slugs. This gave a recirculating charge plus residue of $700 \mathrm{~g}$. The residue amounted to about $5 \%$ of the finished fuel slug weight, or $120 \mathrm{~g}$ per charge, leaving about $580 \mathrm{~g}$ of material to be remelted as the recirculating charge. This consisted of the sprue ends of the castings and any alloy which remained behind in the distributor runners.

Method of Alloy Addition

Several methods of adding zixconium to the furnace charge were tried. The addition of massive pieces of zirconium or of fine cuttings to the furnace charge resulted in segregation of the castings and poor alloy recovery. This appeared to be due to the tendency of zirconium to float, unmelted, to the top of the molten uranium, where it became covered with dross and oxide and dissolved very slowly.

A method which overcame the above difficulty and was satisfactory in production was to swage the crystal bars of zirconium down to wire about $0.090^{\prime \prime}$ in diameter. This was then wound on a mandril the size of the stopper rod, making a mass which would fit around the stopper rod in the bottom of the crucible. The uranium was placed on top of the wire so that the zirconium was held under the molten surface by the weight of the unmelted uranium. The large surface allowed the zirconium to dissolve rapidly.

\section{Crucibles}

MgO crucibles were somewhat more heavily attacked by the $2 w / 0$ zir conium alloy than by the unalloyed uranium. Small thoria crucibles were found to be very satisfactory for melting and casting these alloys in preliminary alloying experiments and for the individually cast slug melts. Thoria crucibles in the $V-2$ size were obtained for test in the centrifugal casting machine. Some of these were very satisfactory. One crucible lasted for six melts. Others broke the first time heated. They were abandoned in favor of the magnesia $V-2$ crucible which was more reliable, although producing slightly dirtier melts.

\section{Pouring Temperature}

The rate of crucible attack increased rapidly as the metal was heated above $1350^{\circ} \mathrm{C}$. About $1425^{\circ} \mathrm{C}$ was the maximum with $\mathrm{MgO}$ crucibles; the metal could be held at that temperature for only a short time. Much higher temperatures could be used with the $\mathrm{ThO}_{2}$ crucibles; melts could be heated to about $1650^{\circ} \mathrm{C}$ without noticeable attack. Temperatures between $1400^{\circ}$ and $1425^{\circ} \mathrm{C}$ produced satisfactory results.

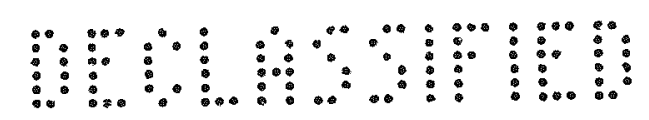




\section{Pouring Rate}

The $V-2$ crucible pour holes were $7 / 16^{\prime \prime}$ in diameter, as received, with a cross sectional area of 0.15 square inches. This diameter hole delivered metal to the 16 castings at such a slow rate that it froze as it flowed into the mold cavities. By enlarging the holes to $7 / 8^{\prime \prime}$ diameter (area $0.60 \mathrm{sq}$. in.) the rate of delivery of metal was increased approximately 4 times, producing smooth, well filled castings. Special $1-1 / 16^{11} \mathrm{di}-$ ametex $\mathrm{MgO}$ stopper rods were obtained for use with these crucibles. It was necessary to raise the stoppex rod with a smooth quick motion.

\section{Vacuum}

The vacuum readings indicated in Table III produced satisfactorily clean metal castings. The surfaces were mirror bright as they were taken from the casting machine and were considered satisfactory for loading directly into the NaK-bonded fuel rod assemblies.

\section{Rotor Assembly and Operation}

\section{Distributor Design}

The first 9 test melts were poured through the original copper distributor with only slight modifications. This distributor could be used only with the radial arrangement of molds. Melt number 9 was made with a Calrod heater in a counterbored space in the bottom of the distributor. The pattern of the distributor vanes required a sharp change in the direction of the metal. The castings showed that the metal was projected down the trailing side of the molds in a thin semi-solidified stream. Many of the castings appeared as masses of crumpled up metal ribbon. Much of the metal was trapped and solidified in the distributor receiver basin and scoops choking off the flow. Enlargement of the nozzles helped to some extent, but it was soon determined that the distributor design and radial arrangement of the molds were basically wrong.

A new distributor was designed to satisfy the following considerations:

a. To convert the velocity due to gravity of the metal poured from the crucible to a radial velocity in the central receiver section of the distributor.

b. To plan the configuration of the vanes in such a way that they would pick up the metal with a minimum of shock and splatter.

c. To accelerate the metal in the vane passages in a uniform, streamlined manner, without abrupt changes in direction.

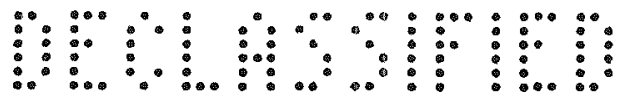


d. To align the molds in the free flight path of the metal so that the metal fills the mold with a minimum of impingement upon the mold walls.

These distributors were made of graphite because of its lower thermal conductivity, high resistance to thermal shock, non-wetting and sticking properties, and ease of machining. The metal was dropped upon an inverted coneshaped elevation of constant negative curvature designed to convert the vertical velocity of the 5 in. fall into a radial velocity away from the center of the rotor. Assuming that this can be done without loss, a vane angle may be calculated which will allow the metal to be picked up in the distributor channels without shock and resultant splatter. This is done as follows:

$$
\begin{aligned}
& \text { (20) } s=\frac{g t^{2}}{2} \\
& s=\text { distance of fall in in. } \\
& g=386^{\prime \prime} / \mathrm{sec}^{2} \\
& \text { (20a) } t=\sqrt{\frac{2 s}{g}}=\sqrt{\frac{2 \times 5}{386}} \\
& \mathrm{t}=\text { time, sec } \\
& =0.161 \mathrm{sec}
\end{aligned}
$$

from which the vertical velocity, equal to the initial radial velocity, may be calculated:

$$
\begin{aligned}
u_{i}=g t & =386 \times 0.161 \\
& =62.1^{\prime \prime} / \mathrm{sec}
\end{aligned}
$$$$
u_{i}=\text { initial velocity of metal }
$$

Taking a radius of the distributor vane openings of $1.25^{\prime \prime}$ and assuming a rotor speed of 500 RPM the tangential velocity of the distributor at this radius may be computed:

$$
\text { (22) } \begin{aligned}
u_{v} & =\frac{2 \times 3.1416 \times 1.25 \times 500}{60} \\
& =65.5^{\prime \prime} / \mathrm{sec}
\end{aligned}
$$

The angle, relative to the radius of the rotor, at which the metal is flowing when it is intercepted by the distrubutor vanes is:

$$
\text { (23) } \begin{aligned}
\phi_{\mathrm{v}} & =\tan ^{-1} \frac{u_{\mathrm{i}}}{u_{\mathrm{v}}}=\tan ^{-1} \frac{62.1}{65.5} \\
\phi_{\mathrm{v}} & =43^{\circ} 30^{\prime} \text { lagging the radial direction }
\end{aligned}
$$


In order to serve their function of increasing the velocity of the metal, the vanes were given a slight increasing angle of attack on the metal stream as the radius increased from vane openings at the receiver to the nozzles at the mold funnels. Thus at the vane openings the vanes intersect the radii at an angle of $44^{\circ}$. The center and radius of curvature of the vanes were selected such that the angle $\phi$ between the metal path and the radial direction decreased gradually to $30^{\circ}$ at the mold openings. The horizontal contour of the vane passages, shown in Figure 11 , section $A_{1}-A_{1}$, blended smoothly from the conical elevation in the receiver to the horizontal at the nozzles. Note that the nozzles should not slope downward as shown in section $A_{2}-A_{2}$ of Figure 11 .

Lag Angle of the Molds

Figure $11^{-c}$ shows a vector diagram giving the direction, with reference to a radius through a nozzle axis, and the velocity of the metal leaving the distributor. The path traced by a metal particle with reference to the horizontal plane of the spinning rotor is the spiral curve indicated. It is not possible to align a straight mold $5^{\prime \prime}$ long in the path in such a way that there is no impingement upon the mold walls. For this reason, and because it was desirable to have the centrifugal force act as nearly axially as possible after filling, the molds were placed at an angle of $35^{\circ}$ lagging the radial direction.

Speed of Rotation

The design of the distributor and the rate at which metal could be supplied from the crucible governed the speed of rotation. When metal was poured from a $7 / 16^{\prime \prime}$ diameter pour hole into the original distributor at 800 RPM, it was projected into the molds as a fine ribbon which solidified as a wadded up, unconsolidated mass. Increased size of the pour hole and lowered speed both improved the condition of the castings. The graphite distributors were designed for a speed of 500 RPM. They seemed to func tion best at a slightly lower speed. The best casting surfaces were obtained when the metal was poured at about 400 RPM with the machine accelerating.

Preheating and Outgassing the Distributor and Molds

Tests 1 to 8 were made without preheating the molds and distributor. There appeared to be a liberation of gas from the mold surfaces. This condition was made much worse by the application of a colloidal graphite wash to the surface of the copper molds. A spirally wound, 1000 watt, Calrod heater was placed in a recess cut in the bottom of the distributor for the subsequent heats. This heated the graphite distributo $x$ to between $300^{\circ} \mathrm{C}$ and $400^{\circ} \mathrm{C}$ and the molds to slightly over $100^{\circ} \mathrm{C}$. This temperature was sufficient to outgas the distributor and mold. 
Cooling, Furnace Disassembly and Casting Extraction

After pouring the melt, the machine was allowed to cool down under vacuum. The molds and castings could be handled with canvas gloves in about $4 \mathrm{hr}$, but there was less discoloration of the castings and of the crucible skull when the equipment was held under vacuum overnight. After cooling, the main valve to the pumps was closed, and inert gas was admitted to the casting machine. Inert gas was used to prevent combustion of the finely divided magnesium which had condensed on the furnace tube,for this occasionally ignited explosively when the vacuum was broken with air.

After binging the machine to atmospheic pressure, the bayonet coupling to the stopper rod was uncoupled; the upper vacuum line was jacked up on the threaded tie rods to clear the furnace tube and swung out of the way. The furnace tube was then removed and the induction coil tipped out of the way on its hinged bus bar. Care was taken in removing the crucible assembly that all of the alloy residues were conserved. The nickel stool and tube assembly were unscrewed from the rotor chamber cover, and the cover was lifted away exposing the rotor assembly. The mold clamps were removed and the upper halves of the molds and the distributor top lifted away.

The castings were numbered in place, and coded with the melt number and the mold number. They were then lifted from the molds. The distributor was transferred in a tray to a glove box where the fine wiry particles could be removed without loss and the distributor cleaned. The castings, the remelt scrap, the residues and ceramics were weighed and a weight balance made against the feed materials.

After completing the normal uranium alloy tests, the casting machine was torn completely apart, cleaned, and reassembled. The vacuum system was cleaned, and the pump oils were changed.

\section{RECOMMENDED SEQUENCE OF OPERATIONS}

The following operational sequence is recommended for production of $2 \mathrm{w} / 0$ zirconium-enriched uranium alloy fuel slugs for the Experimental Breeder Reactor.

\section{A. Charge Preparation}

1. Materials

(a) $93 \%$ U -235 enriched uranium reduction buttons.

(b) Clean, grade 2 or grade 3 iodide crystal bar zirconium swaged to $0.090^{\prime \prime}$ diameter.

(c) Remelt $2 \mathrm{w} / 0 \mathrm{Z} r$-enriched uranium scrap if available. 
(d) MgO ceramics; V-2 crucible, 1-1/16" dia. stopper rod, crucible cover and pedestal all of AEC "product dew."

(e) Liquid nitrogen.

2. Equipment

(a) Hooded hydraulic press with fixtures for breaking reduction buttons.

(b) $5 \mathrm{~kg}$ capacity analytic balance.

(c) 200 g capacity analytic balance.

(d) Large mouthed, 3-1iter Dewar flask.

(e) Sample bottles.

(f) Mandril and lathe for winding zirconium wire.

3. Operation

(a) Reduction buttons.

(1) Weigh to nearest milligram.

(2) Chill buttons in liquid nitrogen.

(3) Break in hooded hydraulic press.

(4) Weigh and sample.

(b) Zirconium wire.

(1) Weigh out $2.15 \mathrm{w} / \mathrm{o}$ of unalloyed uranium weight of zirconium wire (makes $2.1 \mathrm{w} / \mathrm{o} \mathrm{Zr}$ in alloy).

(2) Wind on 1-1/16" mandril making a compact mass which wall fit into the bottom of the crucible.

(3) Check weight.

(c) Remelt scrap.

(1) Weigh, recording weights and batch numbers of each lot.

(d) Insert the stopper rod into the zirconium coil and seat it in the crucible pour hole.

(e) Pack the remelt scrap and broken reduction buttons in the crucible loosely above the zirconium.

(f) Place the crucible assembly upon the stool of the casting machine and assemble the furnace over it.

B. Melting and Casting

1. Equipment

(a) Centrifugal casting machine and auxiliary equipment as described in the report.

2. Operation

(a) Evacuate the centrifugal casting equipment to between $10^{-4}$ and $10^{-5} \mathrm{~mm}$ of $\mathrm{Hg}$ before heating. 
(b) Start the motor-generator at about $1.0 \mathrm{kw}$ input, and increase the input at a rate to give approximately $700^{\circ} \mathrm{C}$ per hr temperature rise, but do not allow the vacuum to rise above 2 or $3 \times 10^{-4} \mathrm{~mm}$ of $\mathrm{Hg}$.

(c) Set mold heater current at 5 amp.

(d) As the temperature increases, take frequent observations of temperature, melt condition, vacuum, etc. At a temperature of about $1425^{\circ} \mathrm{C}$ lower the power to about $5 \mathrm{kw}$ to allow the temperature to drop slowly, to decrease the violence of the stirring action in the crucible, and to allow the dross to separate.

(e) Start the rotor at about 400 RPM.

(f) At $1400^{\circ} \mathrm{C}$ metal temperature, increase the rotor power setting to $60 \%$ and simultaneously lift the stopper rod. The rotor speed should accelerate to $600 \mathrm{RPM}$. Hold at this speed for about 3 min. Cut power to the rotor.

(g) If the ceramics are to be saved, cool at a rate not faster than $1000^{\circ} \mathrm{C}$ per hr.

(h) Shut off H.F. generator, when crucible no longer glows, and cool under vacuum for at least $4 \mathrm{hr}$, preferably overnight.

(i) Disassemble the furnace and remove the castings, remelt, and residues as described on page 24 .

\section{Casting Inspection}

1. Equipment

(a) Gamma source $\left(0.5\right.$ curie $\left.\mathrm{Co}^{60}\right)$.

(b) Balance as shown under $\mathrm{A}-2$.

2. Operation

(a) Weigh the castings, return scrap, and residues including the ceramics. Balance against feed weights.

(b) Inspect the castings visually for surface defects.

(c) Gamma radiograph for internal defects.

\section{Parting Casting Tops and Machining}

1. Equipment

(a) Hooded lathe.

(b) Hooded hydraulic press with breaking fixture.

(c) Balances. 
2. Material

(a) Liquid nitrogen.

3. Operation

(a) Notch the casting $4.300^{\prime \prime}$ from the bottom except for 4 slugs from each heat. Notch these $4.400 "$ from the bottom for sampling. The notches should be cut with a $60^{\circ}$ sharp, carbide threading tool to a depth of at least $0.050^{\prime \prime}$ on the radius.

(b) Immerse the slugs in liquid nitrogen until cooled through.

(c) Snap tops from casting at the notches using the breaking fixture (See ANL-4817).

(d) Sample the long slugs making composite sample of about $2 \mathrm{~g}$ from the tops of the 4 castings and a second composite sample of about $2 \mathrm{~g}$ from the bottoms of the 4 castings. Place samples in the tared weigh bottles provided.

(e) Machine all of the slugs to $4.250^{\prime \prime} \pm 0.001^{\prime \prime}$ length.

(f) Weigh the slugs, the casting croppings as return scrap, and the turnings as residue; include weight of the samples and balance to casting weight before operation.

\section{E. Final Inspection}

1. Equipment required.

(a) Comparator.

(b) Micrometers.

(c) Gage blocks.

(d) $200 \mathrm{~g}$ capacity automatic analytical balance.

(e) $200 \mathrm{~g}$ capacity analytic balance fitted for density meas urement.

(f) Density standards.

(g) Rockwell hardness tester.

2. Material

(a) Density testing medium, $\mathrm{CCl}_{4}$ used.

3. Operation

(a) Measure each slug, to $0.0001^{\prime \prime}$ if possible.

(b) Weigh each slug to the nearest $0.0001 \mathrm{~g}$.

(c) Measure the density of each slug.

(d) Measure the Rockwell "A" hardness of the slugs.

(e) Reinspect the slugs for visual defects. 


\section{ENRICHED URANIUM-ZIR CONIUM ALLOY SLUGS}

Three heats of $2 \mathrm{w} / \mathrm{o}$ zirconium-enriched uranium were centrifugally cast and processed through to finished slugs to test the above operational sequence and to train operating personnel before turning the process over for production. A set of data from the third of these heats and which is believed to show typical performance of the process is presented on pages 29 to 34. The castings made in this heat are shown in Figure 20. Figure 21 shows the condition of the cast surface before removal from the mold. The surface markings are typical. 
Process Data - CP-4 Fuel Manufacture Charge Preparation and Sampling

All Weights are in Grams

\section{New Material}

Button No.

S. M. Batch No.

Wt. As Received

Analytical Sample

Wt. to Charge (Diff.)

Total

Tare and Broken Pieces

Tare Weight

Broken Pieces to Charge

Total

Difference by Weight Balance

Remelt Scrap

Casting No.

Batch No.

Wt. As Received

Wt. As Cleaned

Wt. in Solution

Total in Charge

Total in Solutions

None Used.
Casting No.

CF 3

S. M. Batch No. 62-725

Date $8-12-53$

Bottom No. 62-620

$\begin{array}{r}62-623 \\ 2381.577 \\ \hline .374 \\ 2381.203 \\ \hline\end{array}$

$62-620$

was pre-broken

2588.025

206.852

2381.173

934.200

208.373

725.127

3107.000

.030

Charge Calculation

\begin{tabular}{|c|c|c|c|c|c|c|c|c|}
\hline & $\begin{array}{l}\text { Lot } \\
\text { No. }\end{array}$ & Grams & $U^{235}$ & $\mathrm{U}^{238}$ & $\mathrm{U}^{234}$ & $\mathbf{Z} x$ & & \\
\hline \multirow{2}{*}{$\mathbf{A}$} & \multirow[b]{2}{*}{$62-623$} & \multirow[b]{2}{*}{2381.173} & 93.20 & 5.82 & 0.98 & & & \\
\hline & & & 2219.253 & 138.584 & 23.336 & & & \\
\hline \multirow{2}{*}{$\mathbf{B}$} & \multirow[b]{2}{*}{$62-620$} & \multirow[b]{2}{*}{725.827} & 93.21 & 5.78 & 1.01 & & & \\
\hline & & & 676.543 & 41.953 & 7.331 & & & \\
\hline \multirow{2}{*}{$\mathrm{C}$} & \multirow[b]{2}{*}{$\# 22 x$} & \multirow[b]{2}{*}{68.226} & & & & 100 & & \\
\hline & & & & & & 68.226 & & \\
\hline D & & & & & & & & \\
\hline \multirow[b]{2}{*}{$\mathbf{E}$} & & & & & & & & \\
\hline & & & & & & & & \\
\hline \multirow{2}{*}{$F$} & & & & & & & & \\
\hline & & & & & & & & \\
\hline \multirow{2}{*}{ G } & & & & & & & & \\
\hline & & & & & & & & \\
\hline \multicolumn{2}{|c|}{ Total Grams } & 3175.226 & 2895.796 & 180.537 & 30.667 & 68.226 & & \\
\hline \multicolumn{3}{|c|}{ Calculated Analysis } & 91.200 & 5.686 & .966 & 2.149 & & \\
\hline
\end{tabular}


Melt No.

CF3

SM Batch No. 62-725

Isotopic and Chemical Analysis

\begin{tabular}{|c|c|c|c|c|c|c|c|c|c|}
\hline$\% \mathrm{U}^{234}$ & $\% \mathrm{U}^{235}$ & $\% \mathrm{U}^{238}$ & $\mathrm{Ag}$ & $\mathrm{Al}$ & $\mathrm{As}$ & $\mathrm{B}$ & $\mathrm{Be}$ & $\mathrm{Bi}$ & $\mathrm{Ca}$ \\
\hline 0.99 & 93.25 & 5.76 & $<1$ & $<10$ & $<10$ & 1 & - & $<.05$ & $<.20$ \\
\hline $\mathrm{Co}$ & $\mathrm{Cr}$ & $\mathrm{Cu}$ & $\mathrm{Fe}$ & $\mathrm{K}$ & $\mathrm{Li}$ & $\mathrm{Mg}$ & $\mathrm{Mn}$ & $\mathrm{Mo}$ & $\mathrm{Na}$ \\
\hline$<5$ & 2 & 30 & 80 & $<20$ & $<1$ & 7 & 8 & $<20$ & $<2$ \\
\hline $\mathrm{Ni}$ & $\mathrm{P}$ & $\mathrm{Pb}$ & $\mathrm{Sb}$ & $\mathrm{Si}$ & $\mathrm{Sn}$ & $\mathrm{Ti}$ & $\mathrm{Zn}$ & & \\
\hline 50 & $20(?)$ & $<1$ & $<1$ & 50 & $<5$ & $<50$ & $<20$ & $2.14 \mathrm{avg}$ & \\
\hline
\end{tabular}

Melting \& Casting

Start Mechanical Pump Going

Date $8-12-53$

Start Diffusion Pumps Going

\begin{tabular}{|c|c|c|c|c|c|c|c|}
\hline Time & $\begin{array}{c}\% * \\
\text { Volts }\end{array}$ & $\begin{array}{c}\% * \\
\text { Amps }\end{array}$ & $\begin{array}{c}\% * \\
\text { Kw }\end{array}$ & $\begin{array}{c}\% * \\
\text { Kilovar }\end{array}$ & $\begin{array}{c}\text { Vacuum } \\
\text { mm. Hg }\end{array}$ & $\begin{array}{c}\text { Temp } \\
{ }^{\circ} \mathrm{C}\end{array}$ & Remarks \\
\hline \hline $12: 50$ & 24 & -- & 6 & +2 & $2.6 \times 10^{-4}$ & $-\infty$ & Mold heater,5a \\
\hline $1: 22$ & 31 & -- & 10 & +3 & $2.2 \times 10^{-4}$ & -- & \\
\hline $1: 50$ & 36 & 39 & 15 & 0 & $2.5 \times 10^{-4}$ & 740 & \\
\hline $2: 05$ & 42 & 46 & 20 & 0 & $1.5 \times 10^{-4}$ & 925 & \\
\hline $2: 20$ & 46 & 50 & 26 & +1 & $1.5 \times 10^{-4}$ & 1075 & Mold heater, 8.5a \\
\hline $2: 40$ & 54 & 60 & 35 & +3 & $1.5 \times 10^{-4}$ & 1275 & \\
\hline $3: 00$ & 62 & 65 & 45 & +6 & $9 \times 10^{-5}$ & 1325 & \\
\hline $3: 10$ & 65 & 68 & 50 & +7 & $9.5 \times 10^{-5}$ & 1400 & \\
\hline $3: 15$ & 65 & 68 & 50 & 7 & $9 \times 10^{-5}$ & 1400 & Poured \\
\hline $3: 25$ & 36 & 44 & 15 & 4 & $9 \times 10^{-5}$ & & \\
\hline & & & & & & & \\
\hline
\end{tabular}

Rotor Speed, RPM

350 accelerating to 600 RPM

Duration of Rotation After Pour $3 \mathrm{~min}$. at 600 RPM

Motor Volts

Amps

Remarks Melt and pour were without event.

*Note: Tocco $\mathrm{M}-\mathrm{G}$ induction unit is metered to show per cent of rated output of $220 \mathrm{~V}, 67.3 \mathrm{amp}$, and $15 \mathrm{KW}$.

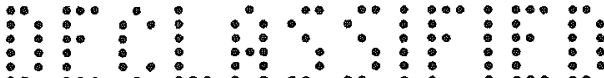


Centrifugal Casting

Melting \& Casting Weight Account
Melt No.

S.M.Batch No. $62-725$

Date 8-12-53 $\begin{array}{cc}\text { Wt. Before } & \text { Wt. After } \\ \text { Melting } & \text { Melting }\end{array}$

3175.226

Furnace Charge

2891.672

Castings (No. 16)

114.430

Tare + Shot + Skull

73.988

Tare

40.442

Shot + Sku1l

Tare + Direct Remelt

313.506

Tare

70.384

Direct Remelt Scrap

243.122

Crucible (New $\mathrm{V}-\mathrm{Z}$ )

1336.602

1335.761

$-0.841$

Stopper

251.753

$251.241 \quad-0.512$

Cover

227.122

$227.068 \quad-0.054$

Spacer

$796.577 \quad 796.582 \quad+0.005$

Total, Castings + Shot + Remelt + Ceramics Difference 3173.034

Difference by Weight (Furnace Residue)

$-1.387$

Remarks Good, no casting difficulties. 
Centrifugal Casting

Visual Inspection \& Radiography
Melt No. CF 3

SM Batch No. 62-725

Date 8-13-53

Gamma Radiogram:

Source Co ${ }^{60}$ Film No Screen Focal Distance $37^{\prime \prime}$ Exposure $2 \mathrm{~h}$

\begin{tabular}{|c|c|c|c|c|}
\hline Casting No. & Visual Inspection & Radiogram & Accept & Reject \\
\hline-1 & Good & Cood & $x$ & \\
\hline-2 & Good & Good & $\mathbf{x}$ & \\
\hline-3 & Good & Good & $x$ & \\
\hline-4 & Good & Good & $x$ & \\
\hline-5 & Good & Good & $x$ & \\
\hline-6 & Good & Good & $x$ & \\
\hline-7 & Good - slight Flow marking & Good & $x$ & \\
\hline-8 & Good & Good & $x$ & \\
\hline-9 & Good & Good & $\mathrm{x}$ & \\
\hline-10 & Good & Good & $x$ & \\
\hline-11 & Good & Good & $x$ & \\
\hline-12 & Good & Good & $x$ & \\
\hline-13 & Good & Good & $x$ & \\
\hline-14 & Good & Good & $x$ & \\
\hline-15 & Good & Good & $x$ & \\
\hline-16 & Good & Good & $\mathbf{x}$ & \\
\hline
\end{tabular}

Casting Accepted for Machining, Number 16 Weight 2891.672

Castings to be Remelted, Number None W eight 
Melt No. CF 3

Casting No. $62-725$

Date $8-14-53$

\section{Inspection of EBR Fuel Slugs}

\begin{tabular}{|c|c|c|c|c|c|c|c|c|c|c|}
\hline \multirow{2}{*}{$\begin{array}{c}\text { Casting } \\
\text { No. }\end{array}$} & \multirow{2}{*}{$\begin{array}{l}\text { Density } \\
\mathrm{g} / \mathrm{cc}\end{array}$} & \multirow{2}{*}{\multicolumn{3}{|c|}{$\begin{array}{l}\text { Hardness } \\
\text { Rockwell A }\end{array}$}} & \multicolumn{2}{|c|}{ Diameter } & \multirow{2}{*}{ Length } & \multirow{2}{*}{$\begin{array}{c}\text { Gross Wt. } \\
\text { grams }\end{array}$} & \multirow{2}{*}{$\begin{array}{l}\text { Net S.F. } \\
\text { grams }\end{array}$} & \multirow{2}{*}{$\begin{array}{l}\text { Net } U^{235} \\
\text { grams }\end{array}$} \\
\hline & & & & & Min. & Max. & & & & \\
\hline 1 & 18.07 & 65 & 66 & 65 & 0.3816 & 0.3861 & 4.2505 & 145.869 & 142.747 & 133.112 \\
\hline 2 & 18.07 & 66 & 64 & 64 & 0.3810 & 0.3861 & 4.2508 & 145.398 & 142.286 & 132.682 \\
\hline 3 & 18.05 & 66 & 64 & 63 & 0.3815 & 0.3852 & 4.2508 & 145.067 & 141.963 & 132.380 \\
\hline 4 & 18.07 & 66 & 65 & 65 & 0.3812 & 0.3856 & 4.2498 & 145.645 & 142.528 & 132.907 \\
\hline 5 & 18.06 & 66 & 65 & 65 & 0.3822 & 0.3856 & 4.2506 & 145.203 & 142.093 & 132.504 \\
\hline 6 & 18.08 & 66 & 64 & 64 & 0.3810 & 0.3866 & 4.2496 & 146.076 & 142.950 & 133.301 \\
\hline 7 & 18.08 & 66 & 64 & 65 & 0.3812 & 0.3845 & 4.2495 & 1444.770 & 141.672 & 132.109 \\
\hline 8 & 18.08 & 66 & 64 & 65 & 0.3842 & 0.3859 & 4.2512 & 146.321 & 143.190 & 133.525 \\
\hline 9 & 18.08 & 65 & 64 & 65 & 0.3833 & 0.3855 & 4.2494 & 146.050 & 142.924 & 133.278 \\
\hline 10 & 18.08 & 66 & 65 & 65 & 0.3832 & 0.3875 & 4.2493 & 145.974 & 142.850 & 133.208 \\
\hline 11 & 18.08 & 66 & 65 & 64 & 0.3822 & 0.3853 & 4.2505 & 145.043 & 141.939 & 132.358 \\
\hline 12 & 18.08 & 66 & 65 & 65 & 0.3810 & 0.3853 & 4.2471 & 145.184 & 142.077 & 132.487 \\
\hline 13 & 18.08 & 66 & 64 & 65 & 0.3835 & 0.3853 & 4.2508 & 145.933 & 142.810 & 133.170 \\
\hline 14 & 18.07 & 66 & 62 & 64 & 0.3841 & 0.3872 & 4.2501 & 147.696 & 144.535 & 134.789 \\
\hline 15 & 18.08 & 66 & 64 & 65 & 0.3818 & 0.3843 & 4.2489 & 144.876 & 141.776 & 132.206 \\
\hline 16 & 18.07 & 65 & 64 & 64 & 0.3822 & 0.3853 & 4.2496 & 145.034 & 141.930 & 132.350 \\
\hline Totals & 289.1818 & 1053 & 028 & 034 & 6.1142 & 6.1716 & 67.9985 & 2330.139 & 2280.272 & 2126.353 \\
\hline Num. Avg. & 18.0739 & 65.8 & 4.3 & 4.6 & 0.3821 & 0.3857 & 4.2499 & 145.634 & 142.517 & 132.897 \\
\hline
\end{tabular}

*These quantities were computed from analytical $r$ esults and are subject to an estimated error of $\pm 0.05 w / 0$. 
Melt No.

CF 3

Casting No. 62-725

Date $8-14-53$

Sprue Removal and Machining

Notching \& Breaking

Weight of Sprues to Remelt

Weight of Turnings + Tare

Weight of Tare

Weight of Machine Turnings
Slug Length 4.250 Notch Depth 0.090

528.119

118.351

92.988

25.363

(By difference 25.345)

\begin{tabular}{|c|c|c|c|c|}
\hline \multirow{4}{*}{ Analytical Samples } & Sample No. & $62-725-5$ & $62-725-6$ & $62-725-7$ \\
\hline & Tare + Sample & 14.655 & 13.451 & 10.535 \\
\hline & Tare Weight & 10.285 & 9.872 & 10.415 \\
\hline & Sample Weight & 4.370 & 3.579 & 0.120 \\
\hline
\end{tabular}

Weight Account of Melt

\begin{tabular}{|c|c|c|c|c|c|c|}
\hline & $\begin{array}{l}\text { Gross } \\
\text { Wt. }\end{array}$ & $\begin{array}{l}\text { w/o } \\
\text { S.F. }\end{array}$ & $\begin{array}{l}\text { Grams } \\
\text { S.F.Wt. }\end{array}$ & $\begin{array}{c}w / 0 \\
v-235\end{array}$ & $\begin{array}{l}\text { Grams } \\
U-235\end{array}$ & Wt. $\%$ \\
\hline Casting Machine Charge & 3175.226 & 97.85 & 3107.000 & 93.20 & 2959.384 & 100.000 \\
\hline $\begin{array}{c}\text { Residue to be Recovered } \\
\text { Shot }+ \text { Crucible Skull }\end{array}$ & 40.432 & 97.85 & 39.563 & 93.20 & 37.683 & 1.273 \\
\hline Turnings & 25.345 & 97.85 & 24.800 & 93.20 & 23.622 & 0.798 \\
\hline $\begin{array}{l}\text { Remelt } \\
\text { Direct Casting Remelt }\end{array}$ & 243.122 & 97.85 & 237.898 & 93.20 & 226.595 & 7.657 \\
\hline Sprues (Casting Tops) & 528.119 & 97.85 & 516.771 & 93.20 & 492.219 & 16.632 \\
\hline Reject Fuel Slugs & -- & & & & & \\
\hline $\begin{array}{l}\text { For Shipment to EBR } \\
\text { Fuel Slugs }\end{array}$ & 2330.139 & 97.85 & 2280.071 & 93.20 & 2171.744 & 73.385 \\
\hline Samples, Etc. & 8.069 & 97.85 & 7.896 & 93.20 & 7.520 & .254 \\
\hline Totals & 3175.226 & 97.85 & 3106.999 & 93.20 & 2959.383 & 99.999 \\
\hline $\begin{array}{l}\text { Total Yield (Remelt and } \\
\text { Residue (for recovery) }\end{array}$ & & & & & $\begin{array}{r}3101.380 \\
73.846\end{array}$ & $\begin{array}{r}97.674 \\
2.326\end{array}$ \\
\hline
\end{tabular}




\section{Discussion of Process Data}

The process forms shown on pages 29 to 34 were prepared for complete and uniform recording of the process, accountability and inspection data. The weight account of the melting and casting operation was made by weighing all of the charged materials and the ceramics. After melting, the castings residues, return scrap and ceramics were again weighed and balanced against the weights before melting. A loss in weight due to volatilization of the magnesium reduced from the crucible must be allowed. This is recorded as a difference figure on page 31 . The results of the visual inspection and radiography are shown on page 32. Slight surface irregularities, not extending into the casting, were consider ed acceptable. Deep folds, pocket cavities and other imperfections which might interfere with $\mathrm{NaK}$ wetting were considered rejectable. Internal porosity was not wanted.

Results of the final inspection are shown on page 33. The densities were measured by the loss of weight method in $\mathrm{CCl}_{4}$. The slug diameters were found to vary a maximum of $\pm 0.003^{\prime \prime}$ instead of the required $\pm 0.0015^{\prime \prime}$. This was found to be in part due to irregular shrinkage and in part due to irregularities in the diameter of the molds. The reading was taken by rolling the slugs under a dial comparator and is somewhat misleading in that it gives undue emphasis to small dips and bumps on the surface.

A resume of the weight account for the batch is shown on page 34. All gross weight were made to the nearest milligram, while the net SF and U-235 quantities were computed from analytical results and are subject to a variation of $\pm 0.05 \%$. Calculation was carried to milligrams for bookkeeping purposes only. Yield and residues produced were as follows:

$$
\begin{array}{lr}
\text { Total Yield, Slugs + Return Scrap } \quad 97.674 \% \\
\text { Total Residues } & 2.326 \%
\end{array}
$$

Thermal Cycling and Metallography of Centrifugally Cast Fuel Slugs

Thermal cycling and metallographic evaluations were made on the centrifugally cast, $2.15 \mathrm{w} / 0$ zirconium-normal uranium fuel slugs by members of the Physical Properties Group. The results of these tests are summarized briefly as follows:

Thermal Cycling

Four centrifugally cast specimens (numbers 16-3,16-6, 16-9 and 16-15) were thermal cycled 200 times between $50^{\circ} \mathrm{C}$ in the "Woosher." The cycle was $15 \mathrm{~min}$ heating $5 \mathrm{~min}$ at $550^{\circ} \mathrm{C}, 5 \mathrm{sec}$ cooling and $5 \mathrm{~min}$ at $50^{\circ} \mathrm{C}$. All specimens grew at a linear rate of $K=10 \mathrm{micro}$ inches/inch/cycle. The surface did not bump or wrinkle. 
Metallography

Specimens from melts number 11,14 and 16 were examined microscopically. A homogeneous, modified acicular structure was observed in all of the specimens, as shown in Figures 22 and 23. Several types of inclusions were observed. The fine white inclusions and gray inclusions seen in Figure 23 were of quite uniform distribution. The specimens from melt No. 16 contained large dross stringers concentrated at the sprue end of the castings. This condition is shown in Figure 24. Melt No. 16 was poured under full induction power.

\section{Suggested Modifications of the Centrifugal Casting Machine}

Several additional modifications are suggested for the centrifugal casting machine. The most time consuming part of the process was the long wait for the hot metal to $c 001$ in the vacuum sufficiently to allow opening the furnace. In 3-shift operation, this would represent a costly waste of time. To speed up the operation and at the same time to improve the vacuum, it is suggested that a liquid nitrogen cold trap with a low resistance, finned, outer surface be installed in the upper vacuum line. Slight modification of the rotor chamber and lower vacuum line would allow its use as a blower housing. The rotor would become a fairly effective impeller when used in a helium atmosphere. After pouring and cooling to reasonable temperature, helium would be admitted to the machine, and the rotor started forcing helium through the vacuum line, past the liquid nitrogen heat exchanger and down through the furnace tube to the rotor again. Cooling should be rapid.

Additional work on the correct mold angle might improve the casting surfaces. 


\section{ACKNOWLEDGEMENT}

The assistance of many persons in the Laboratory is acknowledged on various phases of the program. "Special credit is due J. L. Armstrong for design details, M. C. Shaw of the Reactor Engineering Division for suggestions on distributor design, Central Shops personnel for construction of the casting machine, W. H. Morris and B. J. Mikolajeski for assistance in operating the equipment and machining the specimens, and to the Physical Properties Group of the Metallurgy Division for thermal cycling and metallography.

\section{REFERENCES}

1. Shuck, A. B., ANL-5185, "The Manufacture of Sixteen Uranium-Zirconium Alloy Test Fuel Rods for EBR $^{20}$ (January 4, 1954)

2. Lichtenberger, H. V., Teletype to F. G. Foote, July 28, 1953.

3. Shuck, A. B., ANL-4617, "Development of Methods for Casting Fabricating Enriched Uranium Fuel Slugs" (April 18, 1951), pp 3-21.

4. Shuck, A. B., ANL-4847, "The Manufacture of Enriched Uranium Fuel Slugs for the Experimental Breeder Reactor" (April 20, 1953), pp 8-20.

5. Robinson, E. L., "Stresses in Turbine Disk Wheels" Mechanical Engineer's Handbook, Fifth Edition (1951) McGraw -Hill: pp 471-477.

6. Timoshenko, S., "Strength of Materials, Part II," Second Edition, Van Nostrand: pp 245-264. 
Figure 1. Statically Cast Fuel Slug

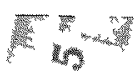

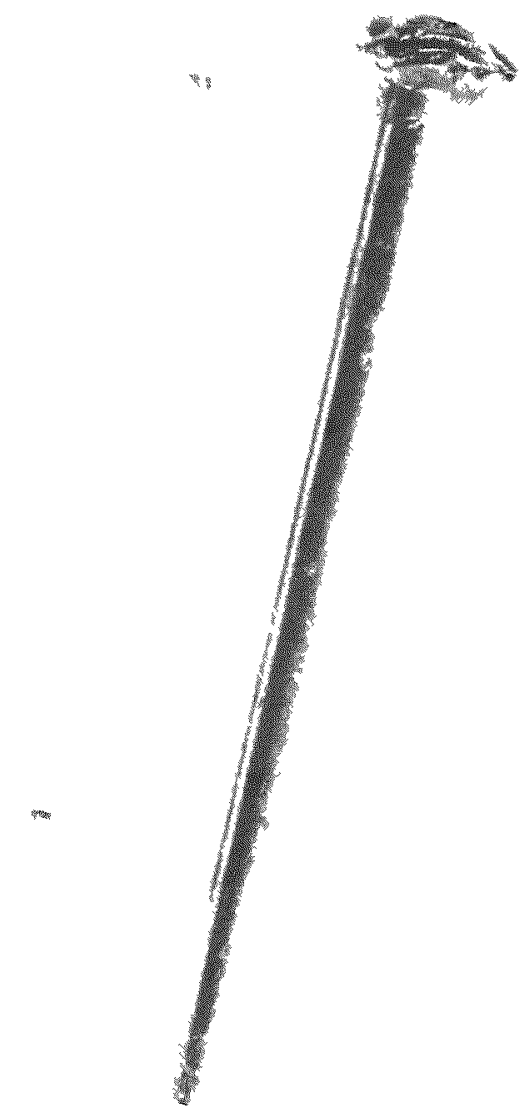

AS 120 
Figure 2. Assembly Drawing (original form) Centrifugal Casting Machine
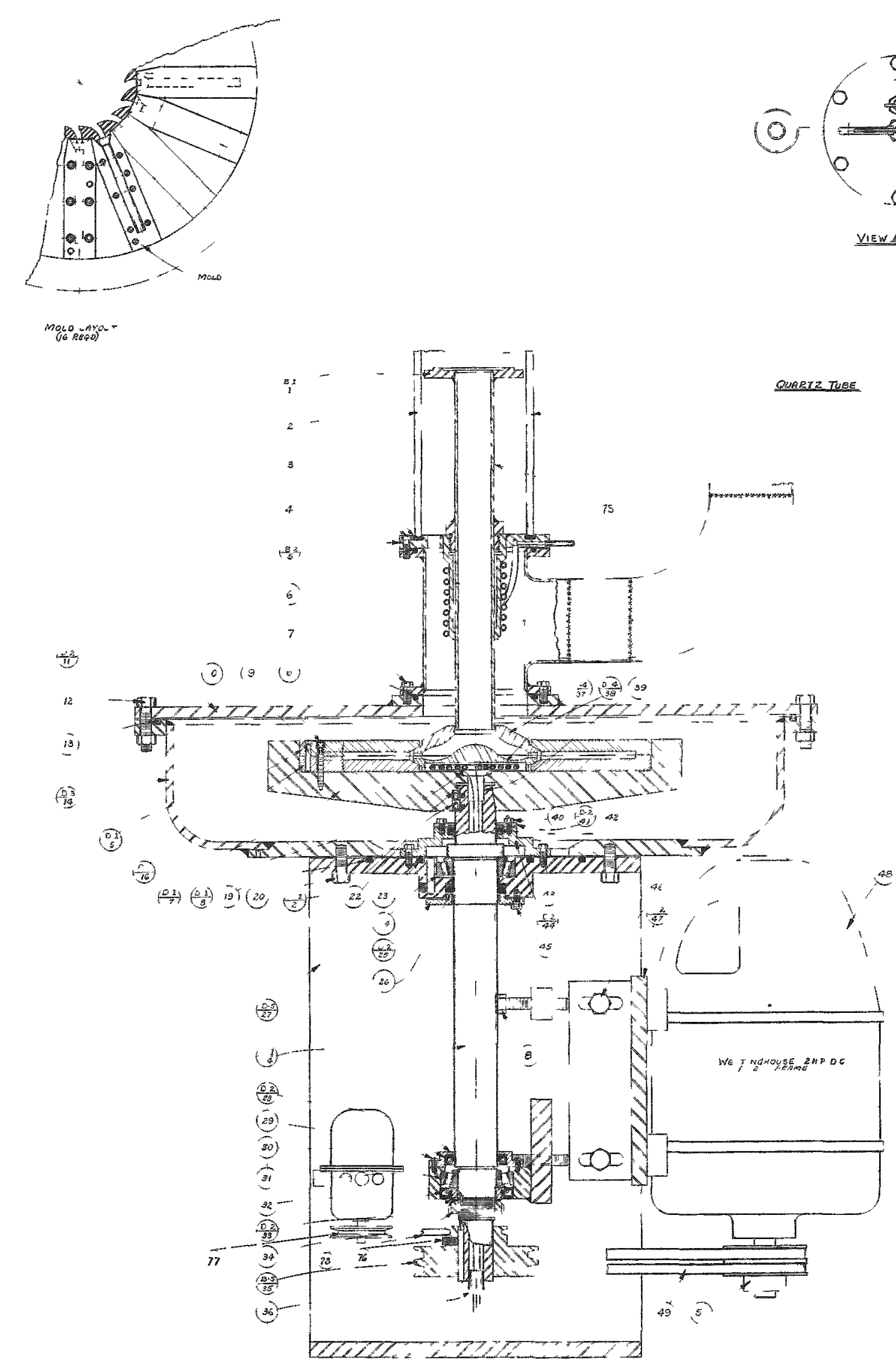
(Drawing MY 1498 DD)

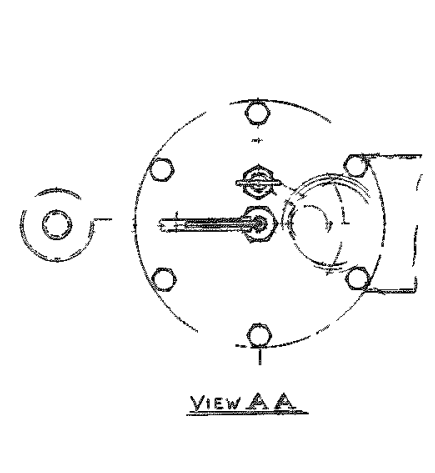$$
\text { (a) }
$$

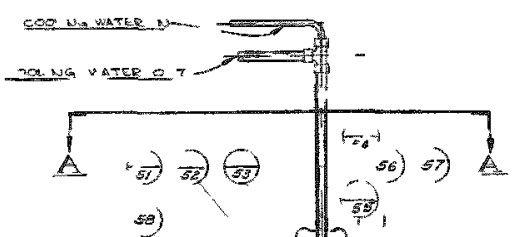

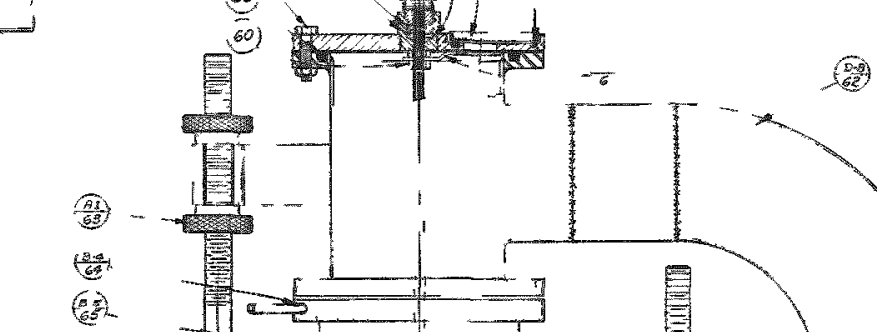

(․․장

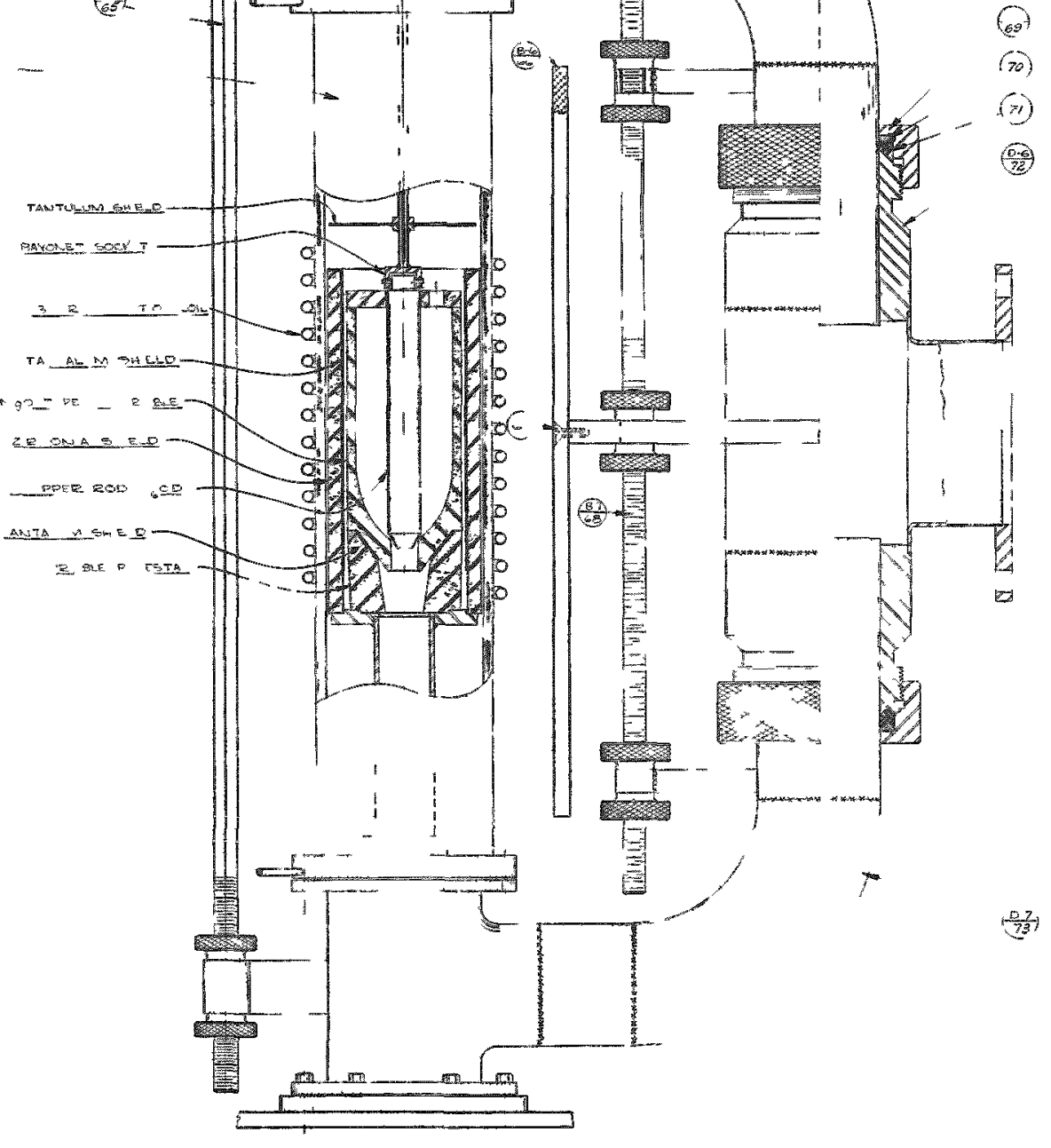

O०णा! 
Figure 3. Centrifugal Casting Machine (Original Form)

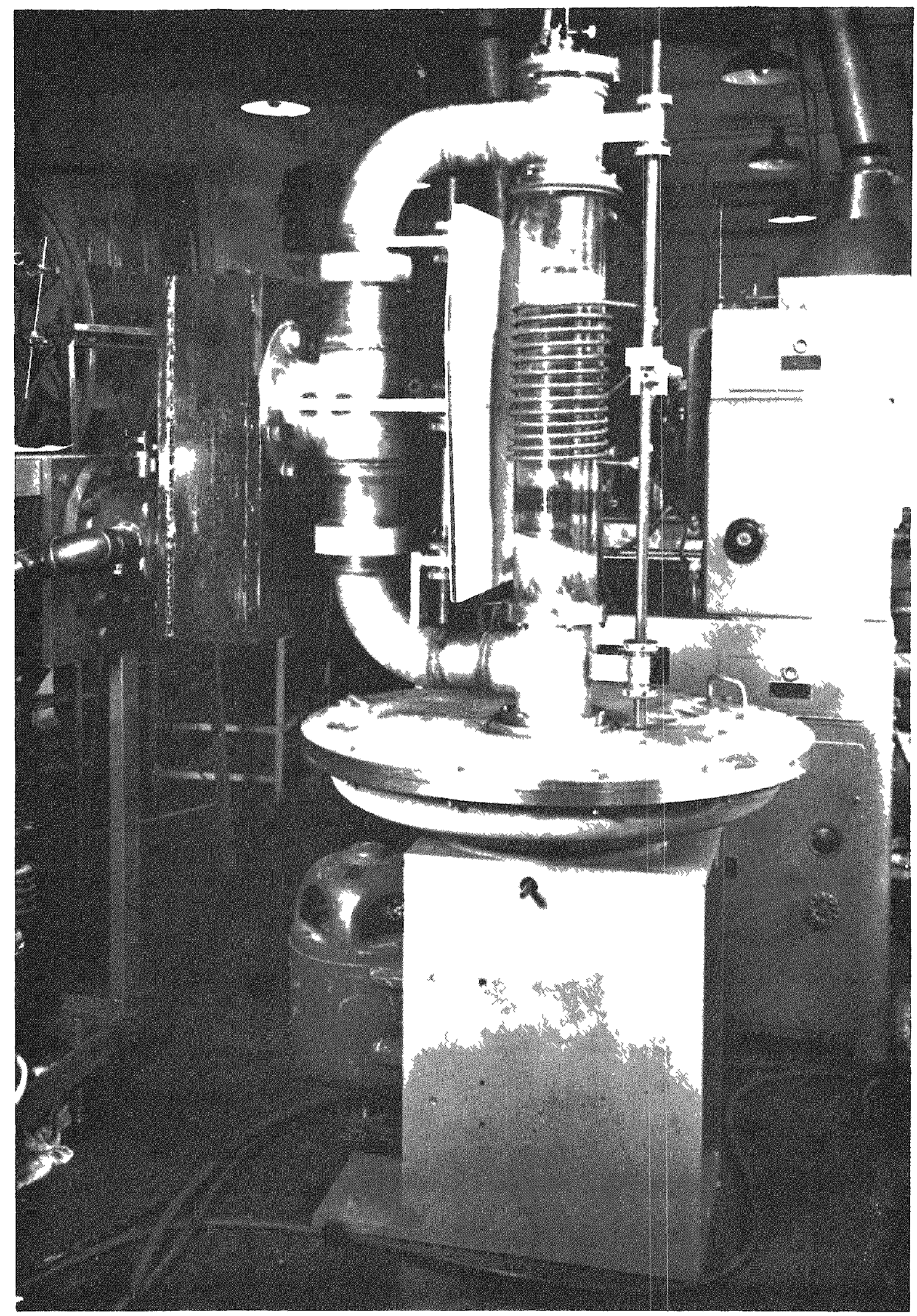

AS 131 


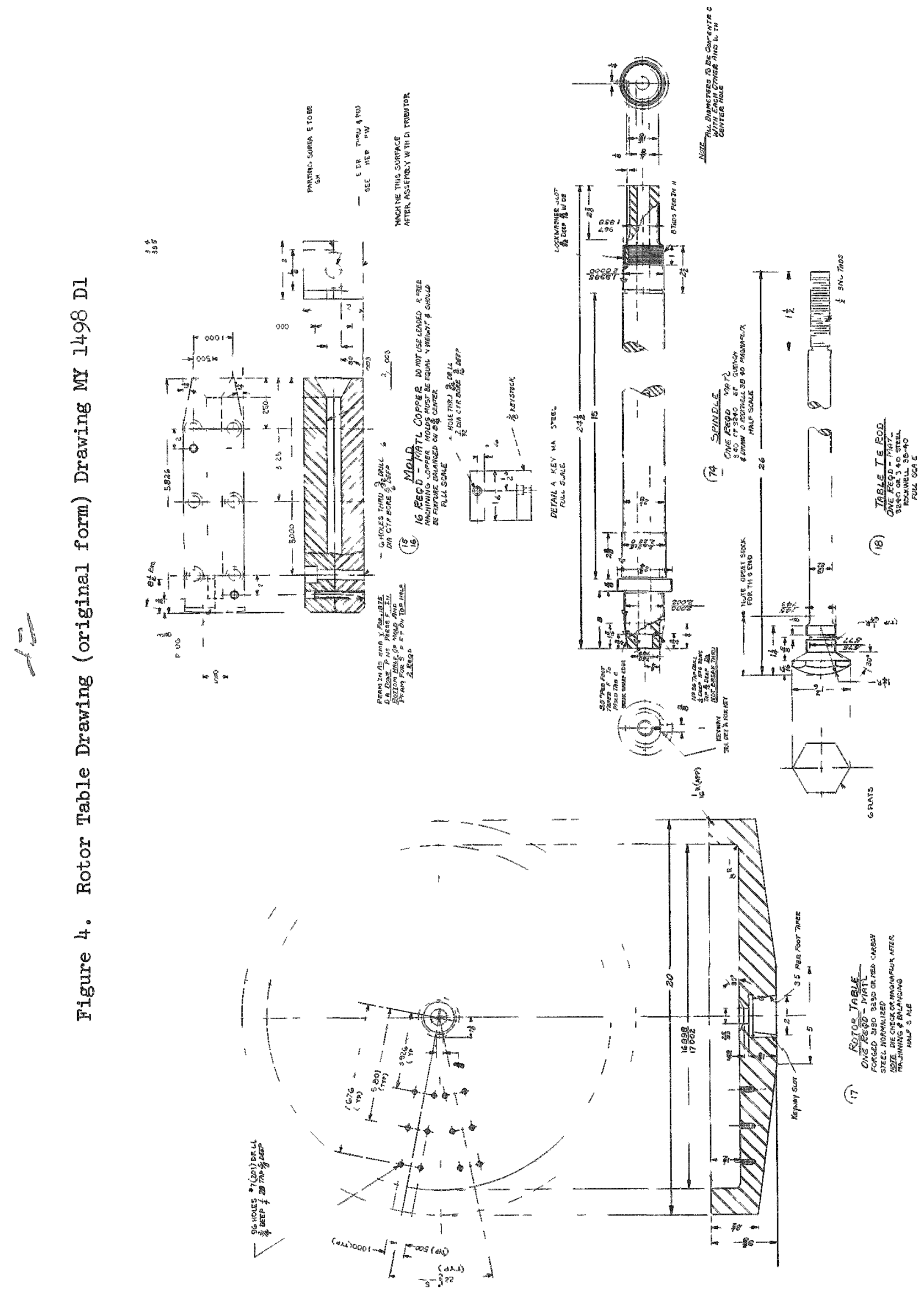


Figure 5. Molds, Distributor and Rotor Table (Radial Assembly)

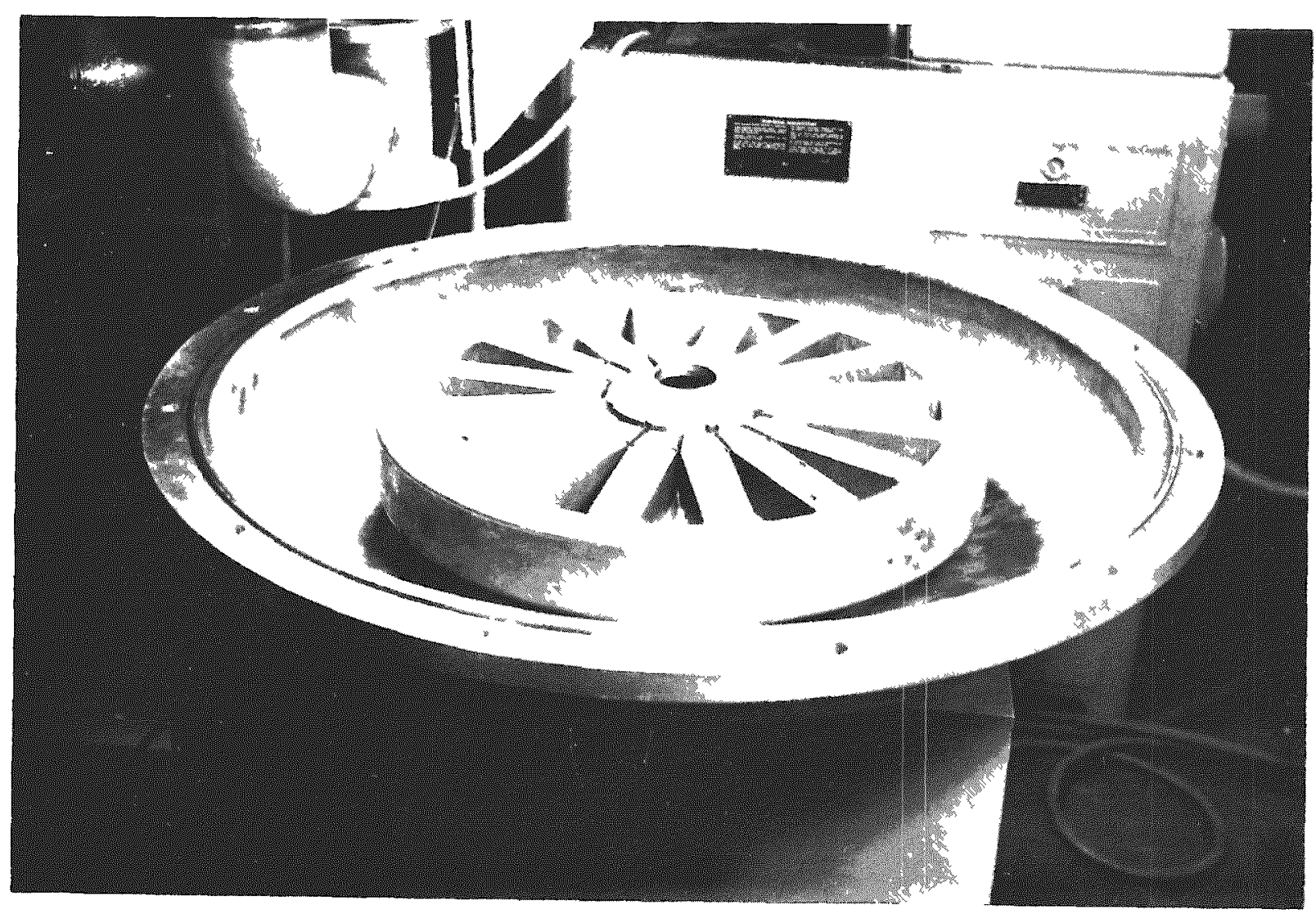

AS 138 


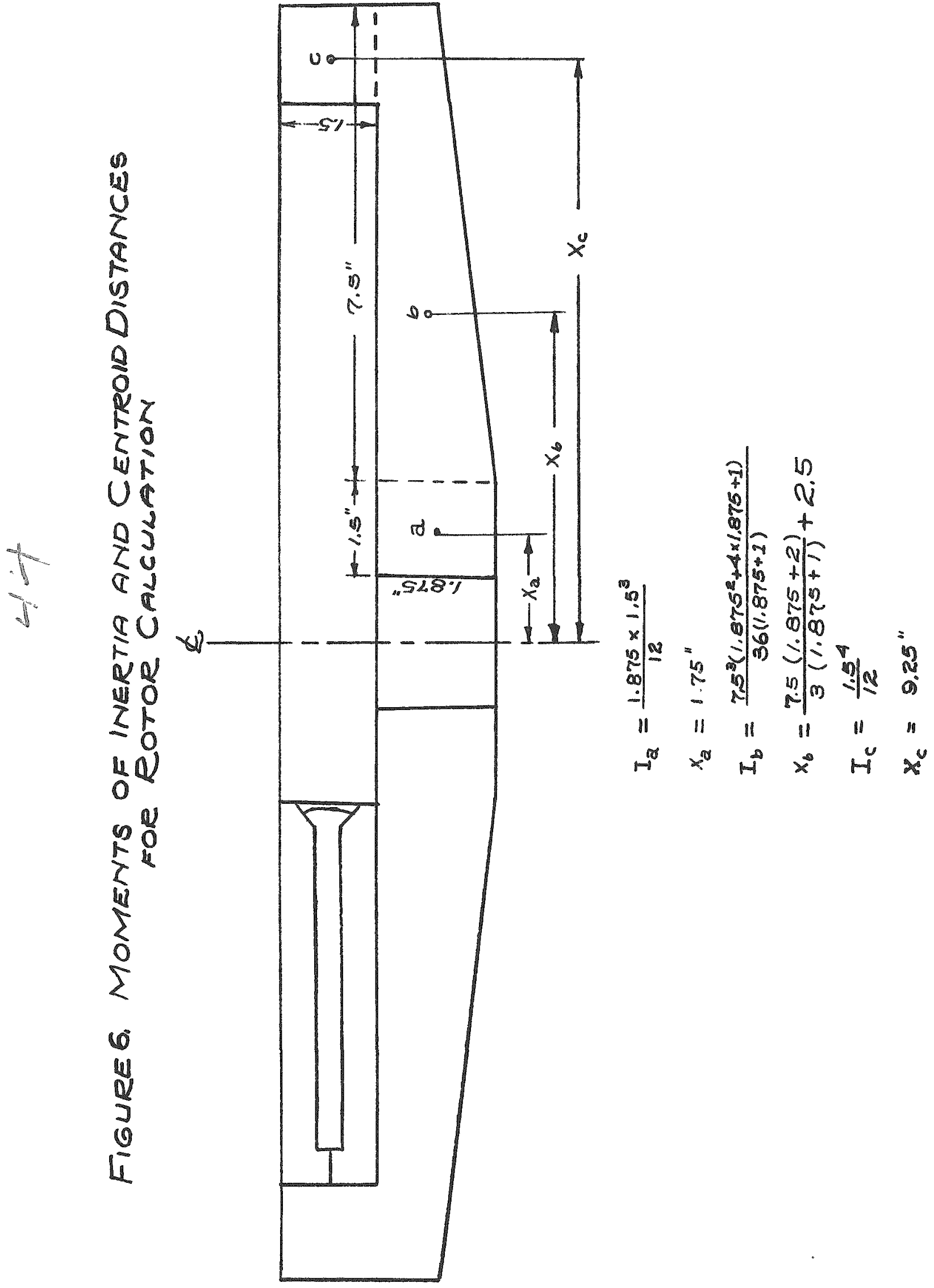




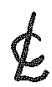

Figure 7

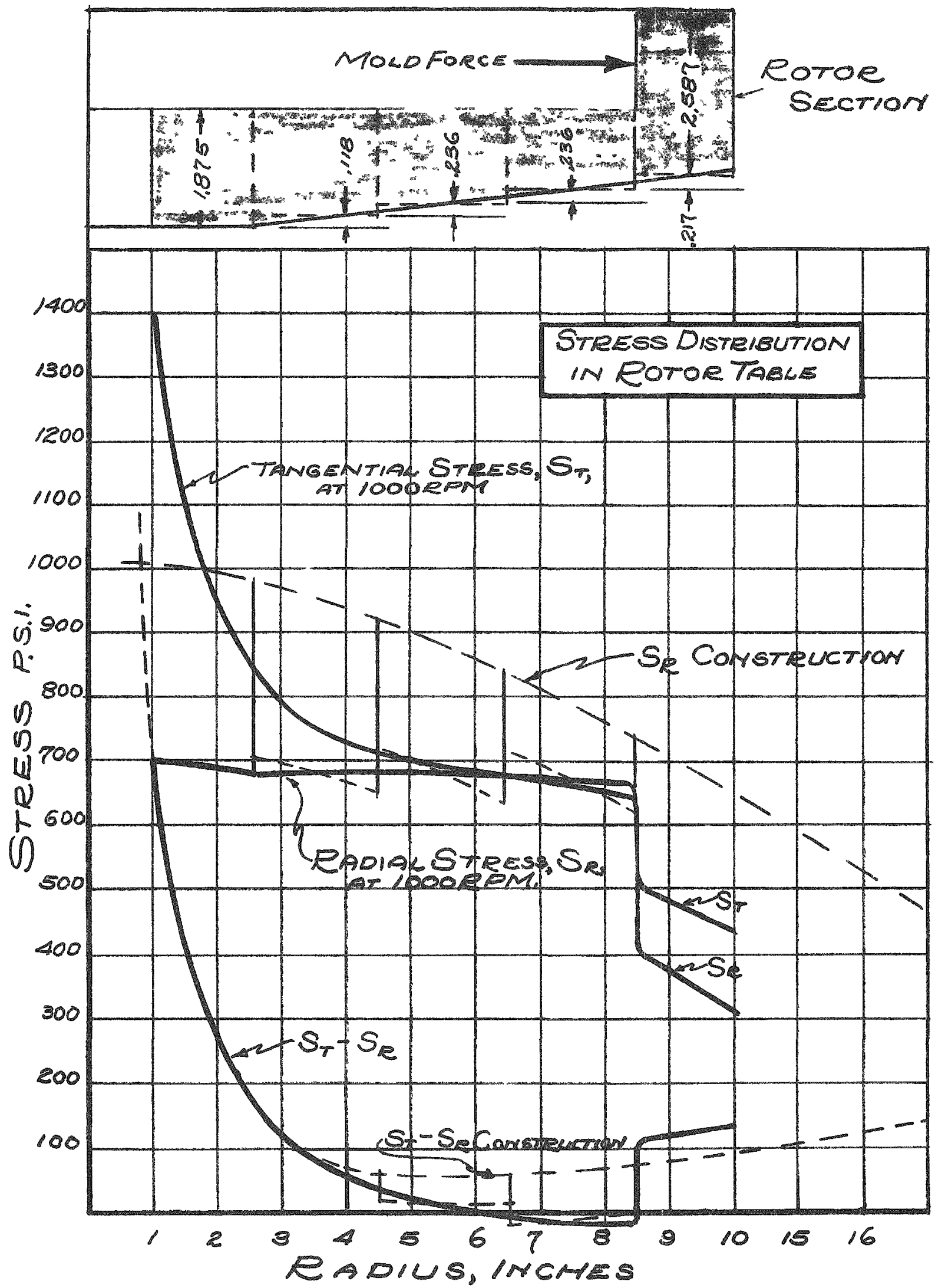

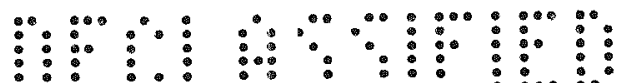


Figure 8. Drive Motor Control Panel

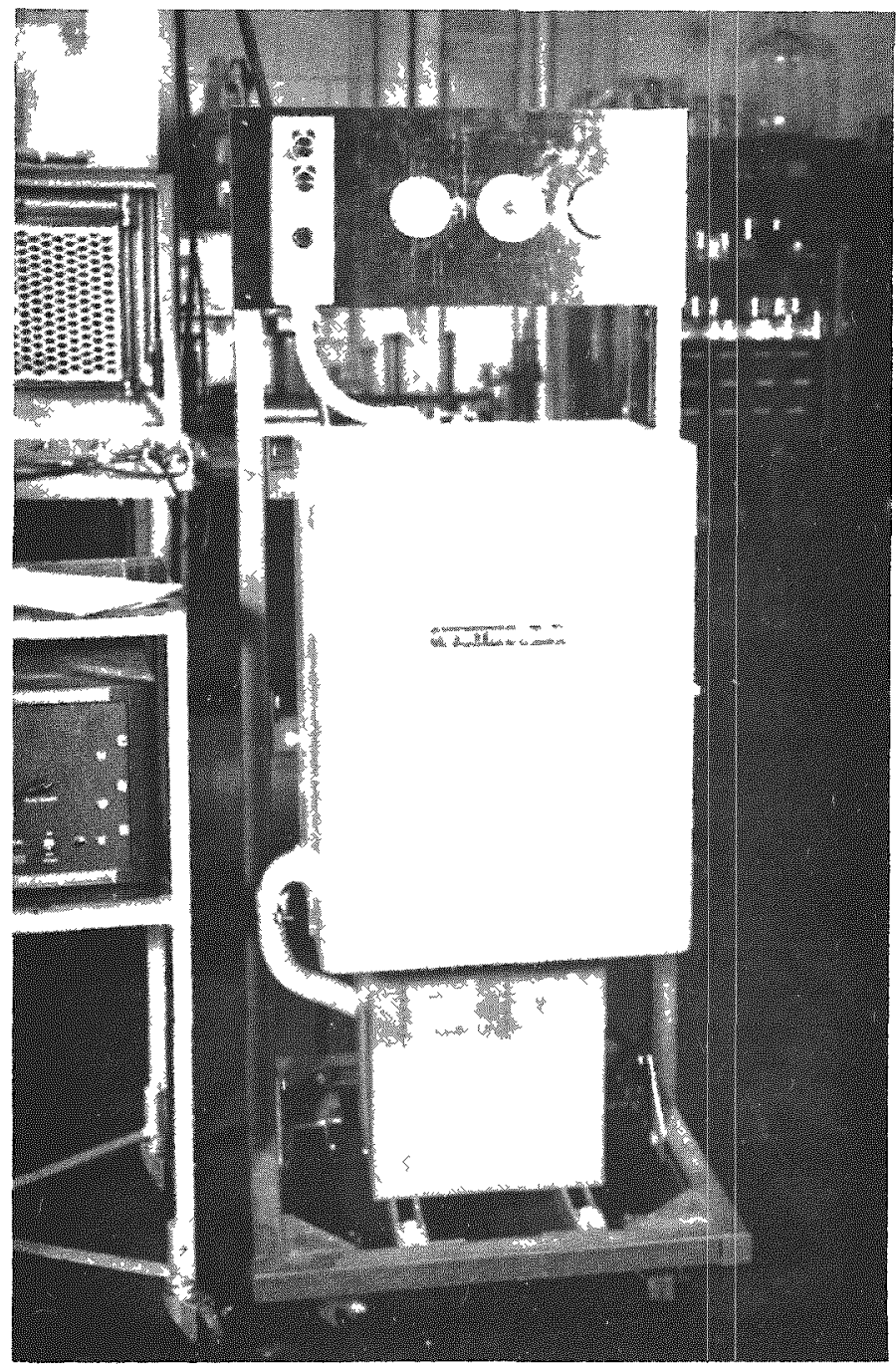

AS 141 
Figure 9-a. Melt No. 4, Poured into Radially Arranged Molds Through Copper Distributor at 800 RPM

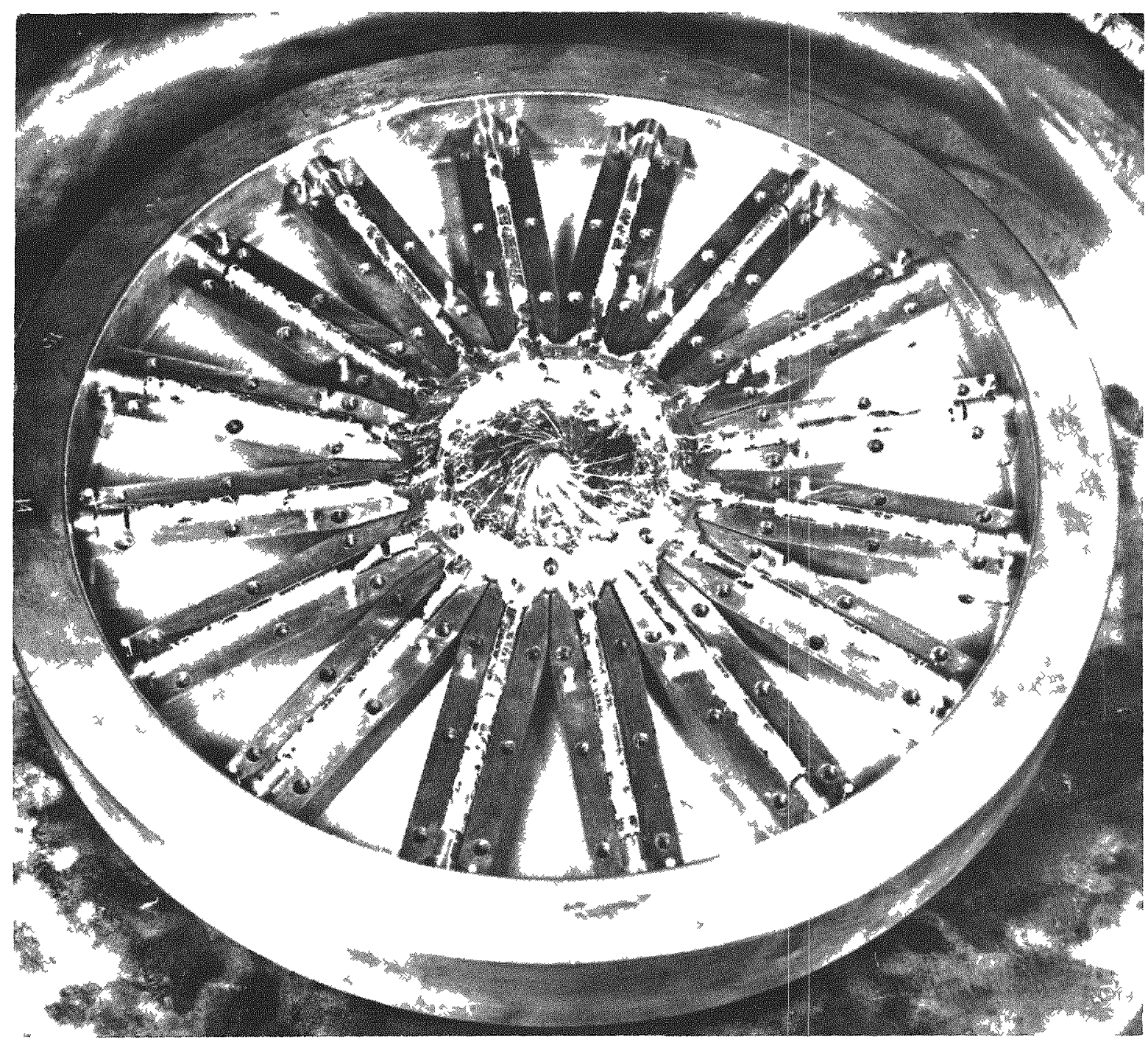

AS 137 
Figure 9-b. Melt Number 9, Poured into Radially Arranged Molds through Copper Distributor at 450 RPM.

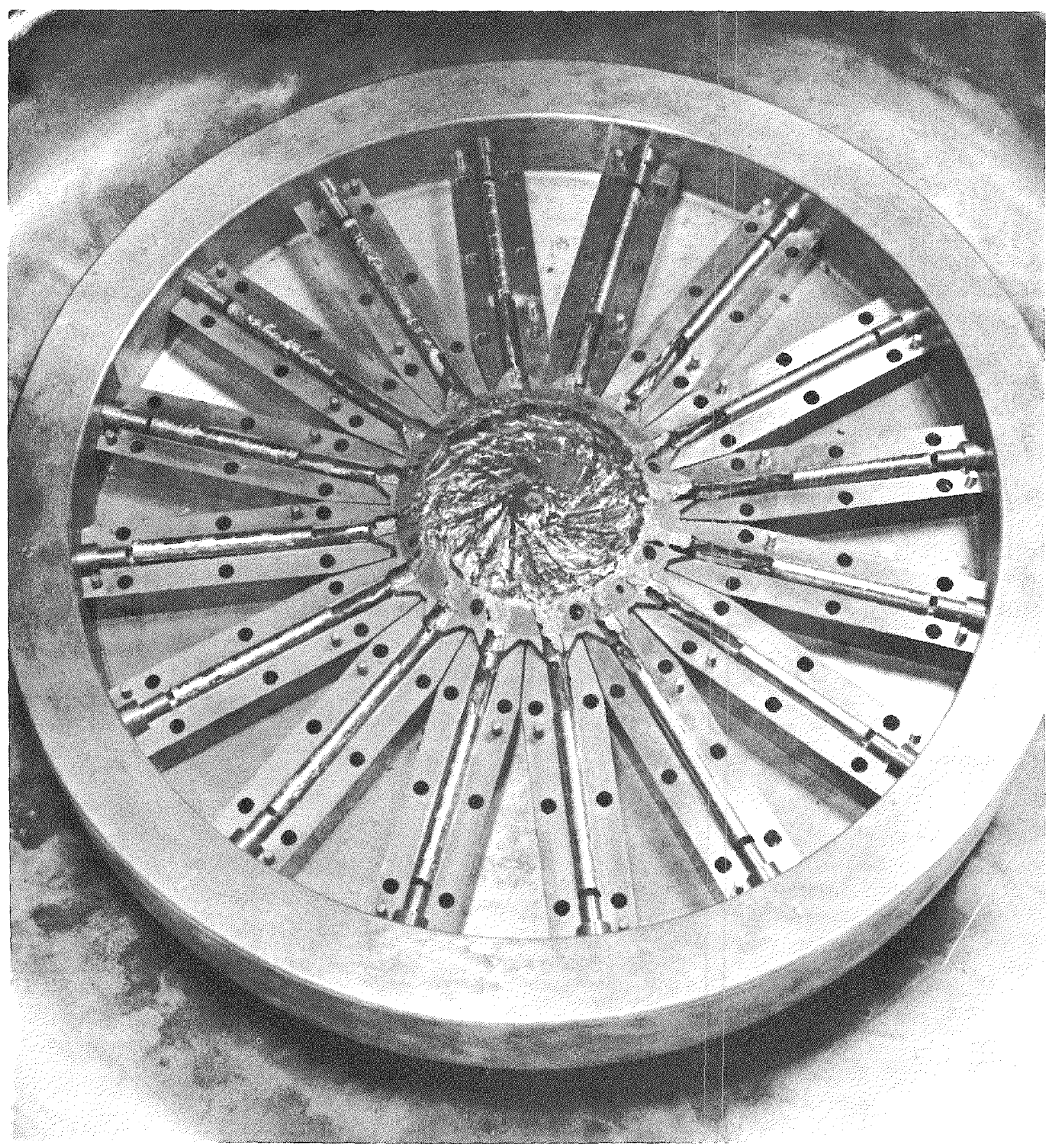

AS 136 

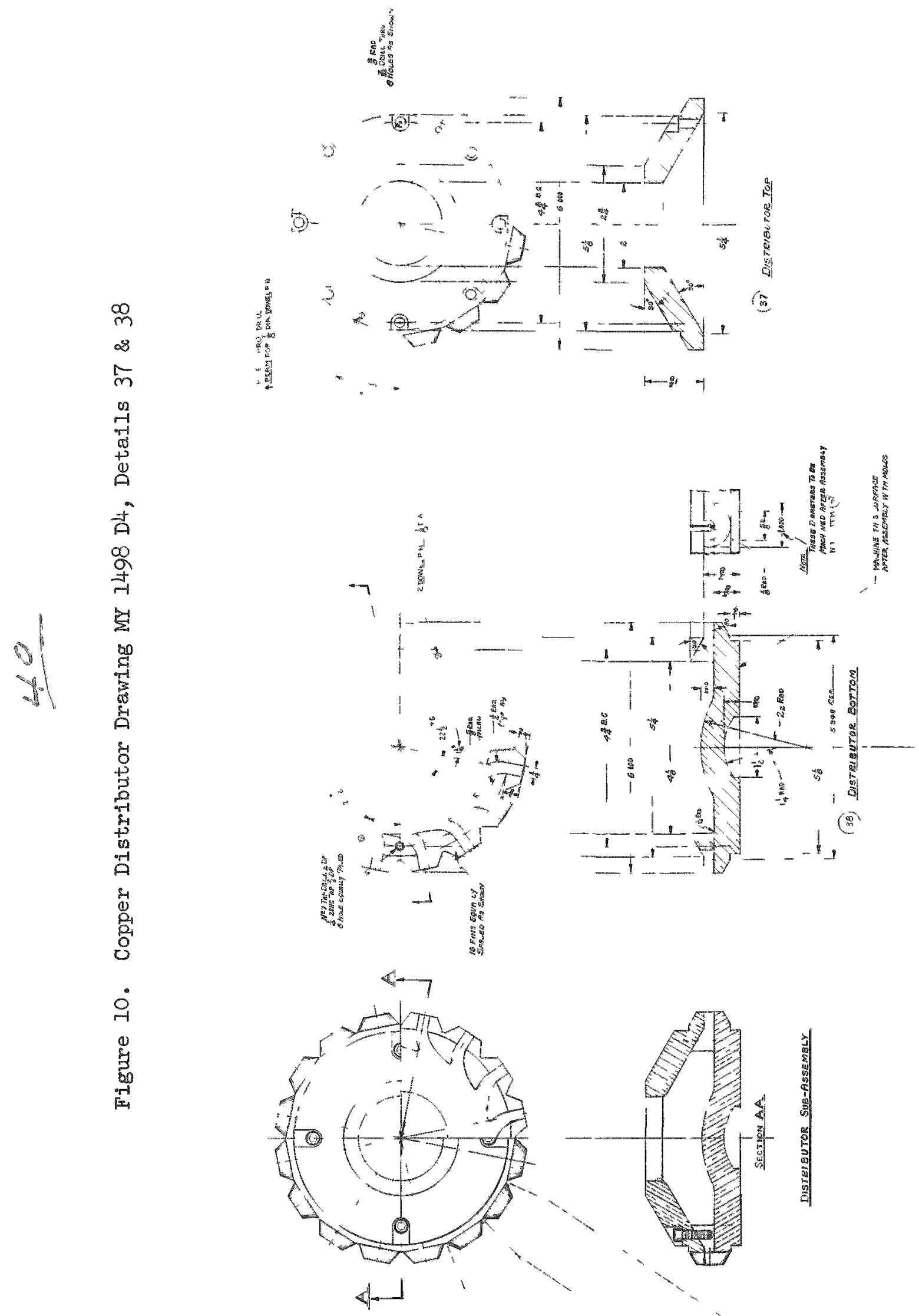


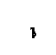

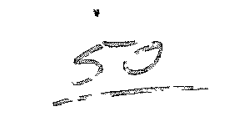

Figure 11. Graphite Distributor Drawing MY 1570 D, Revision A
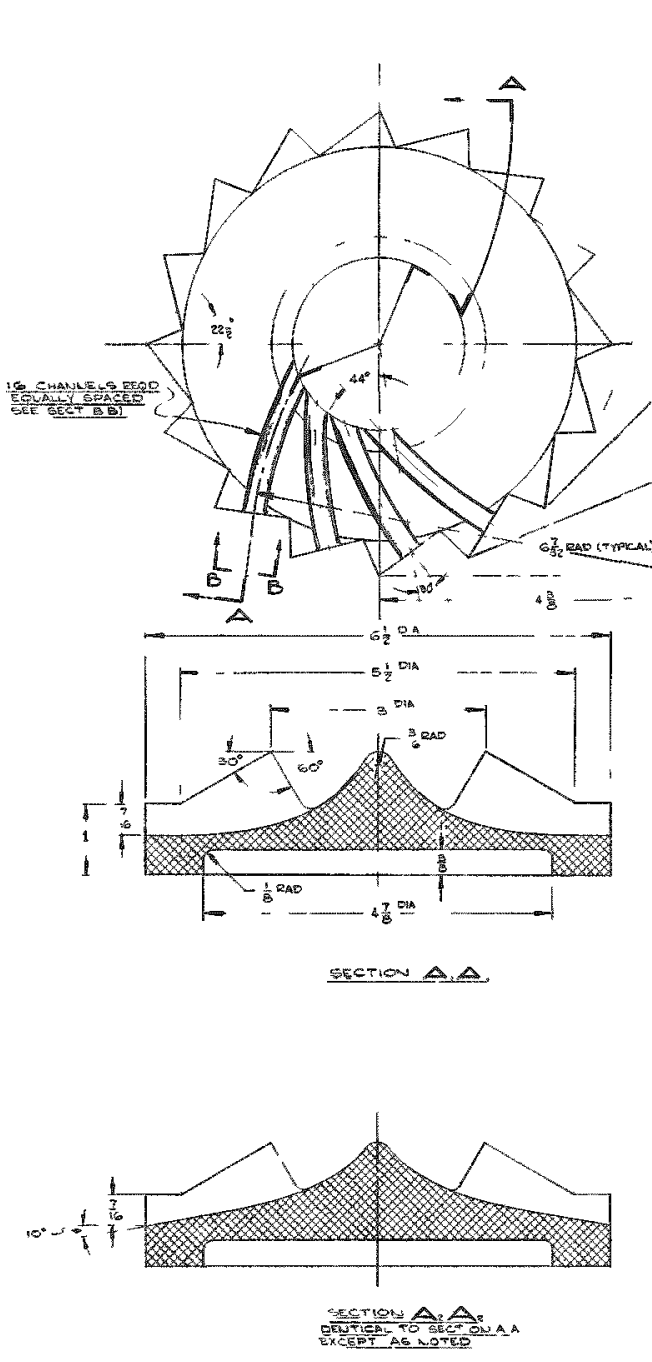

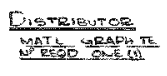

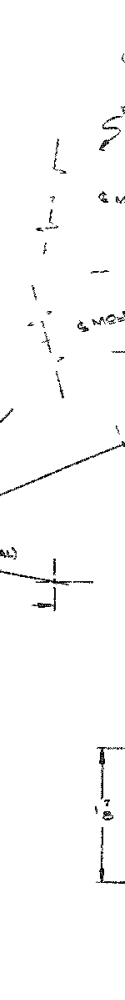

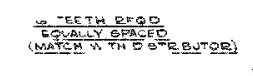
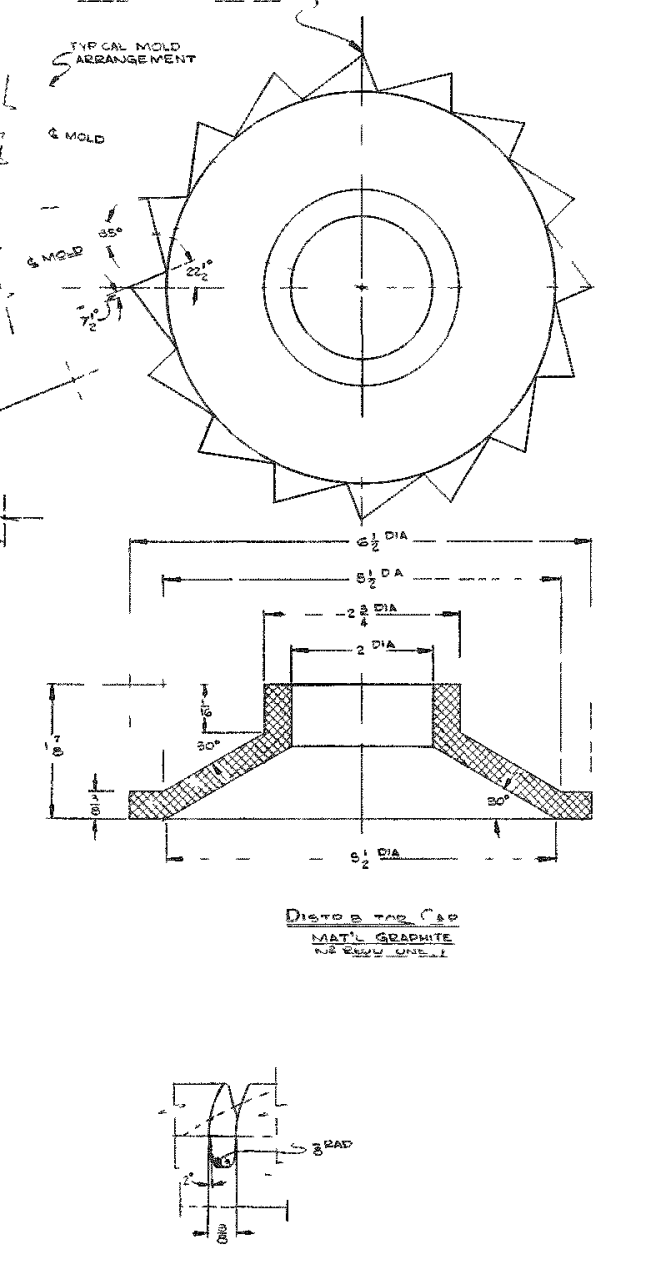

Sctrien B-B

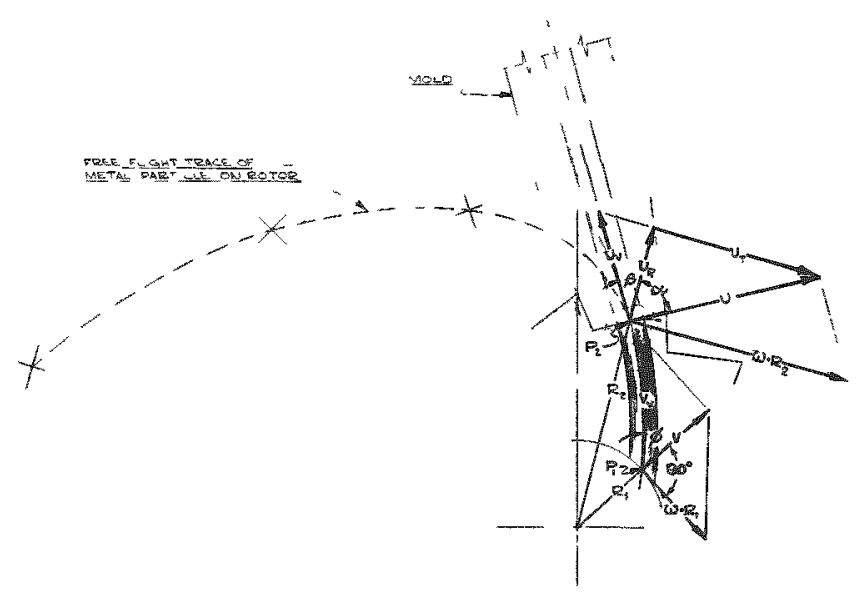

VELCETYY DIATEAM

AI PONT :

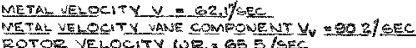
EALU:

ATONT 2.

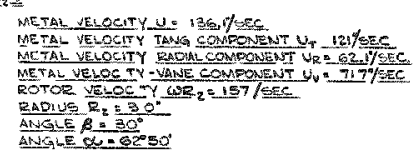


Figure 12. Graphite Distributor
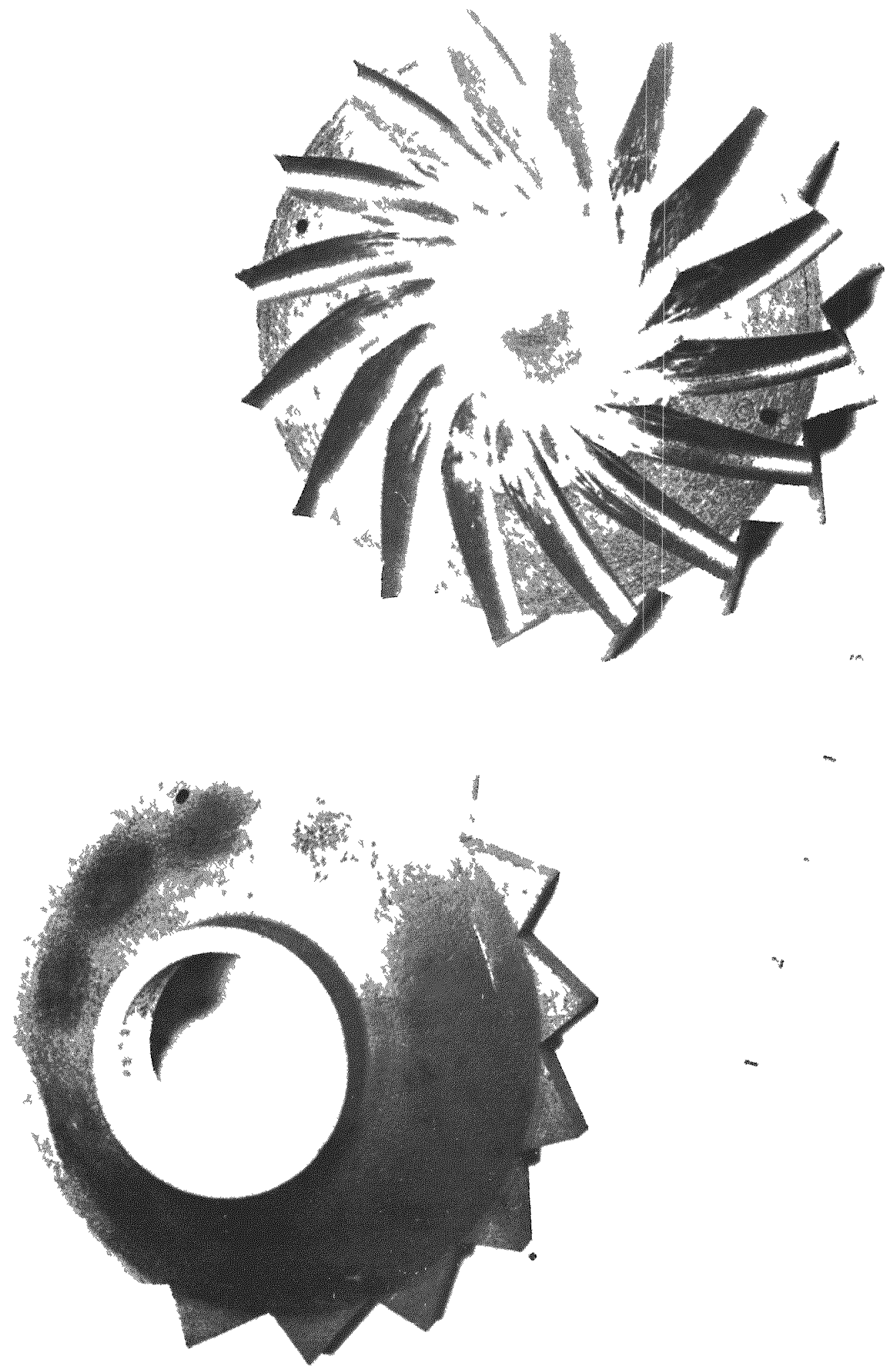

AS 142 


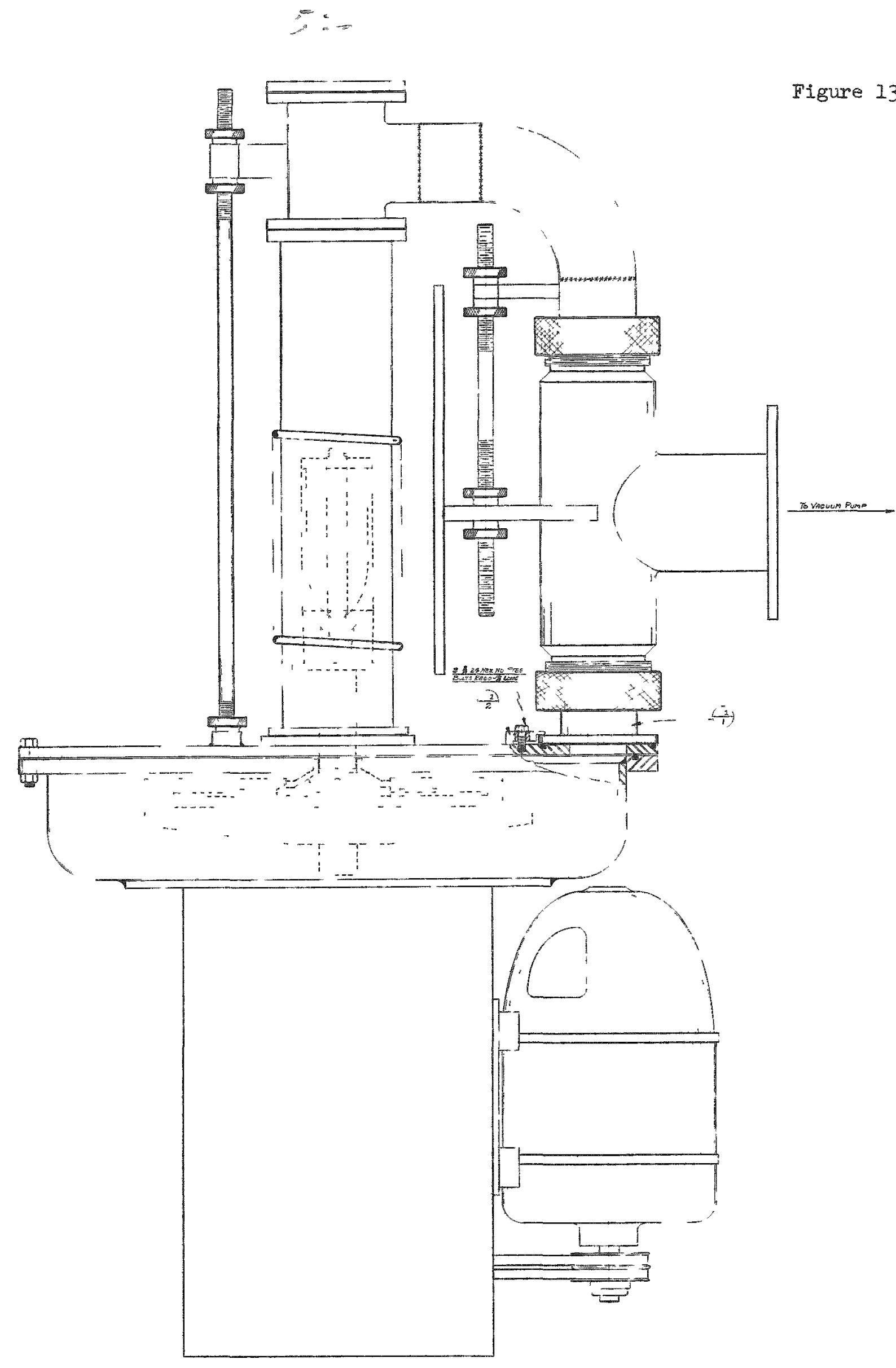

Revised Assembly of the Centrifugal Casting Machine Drawing No. MY 1570 DD

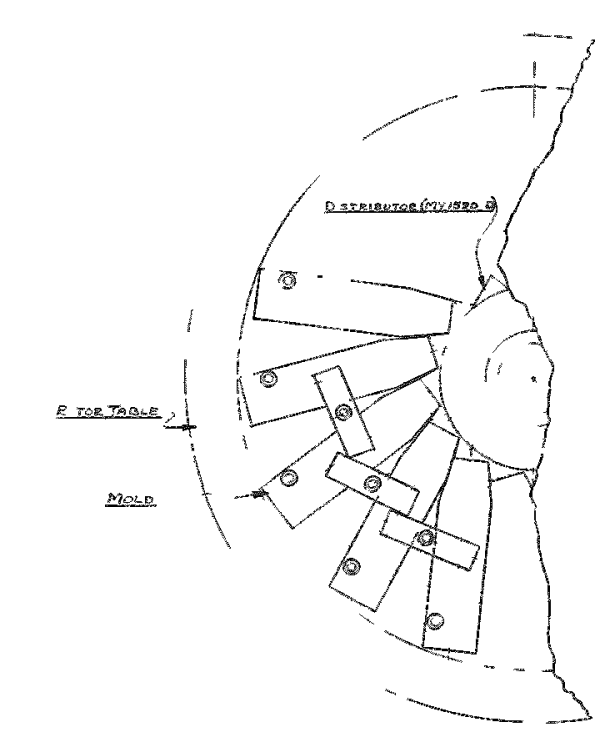

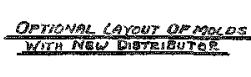

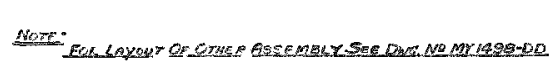

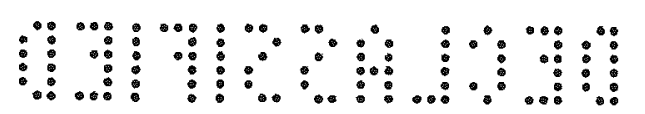

(4) 
Figure 14. Rotor Table, Graphite Distributor and $35^{\circ}$ Inclined Molds. Eight of the Molds and the Distributor are open to show the contour of the molds and position of the mold cavities.

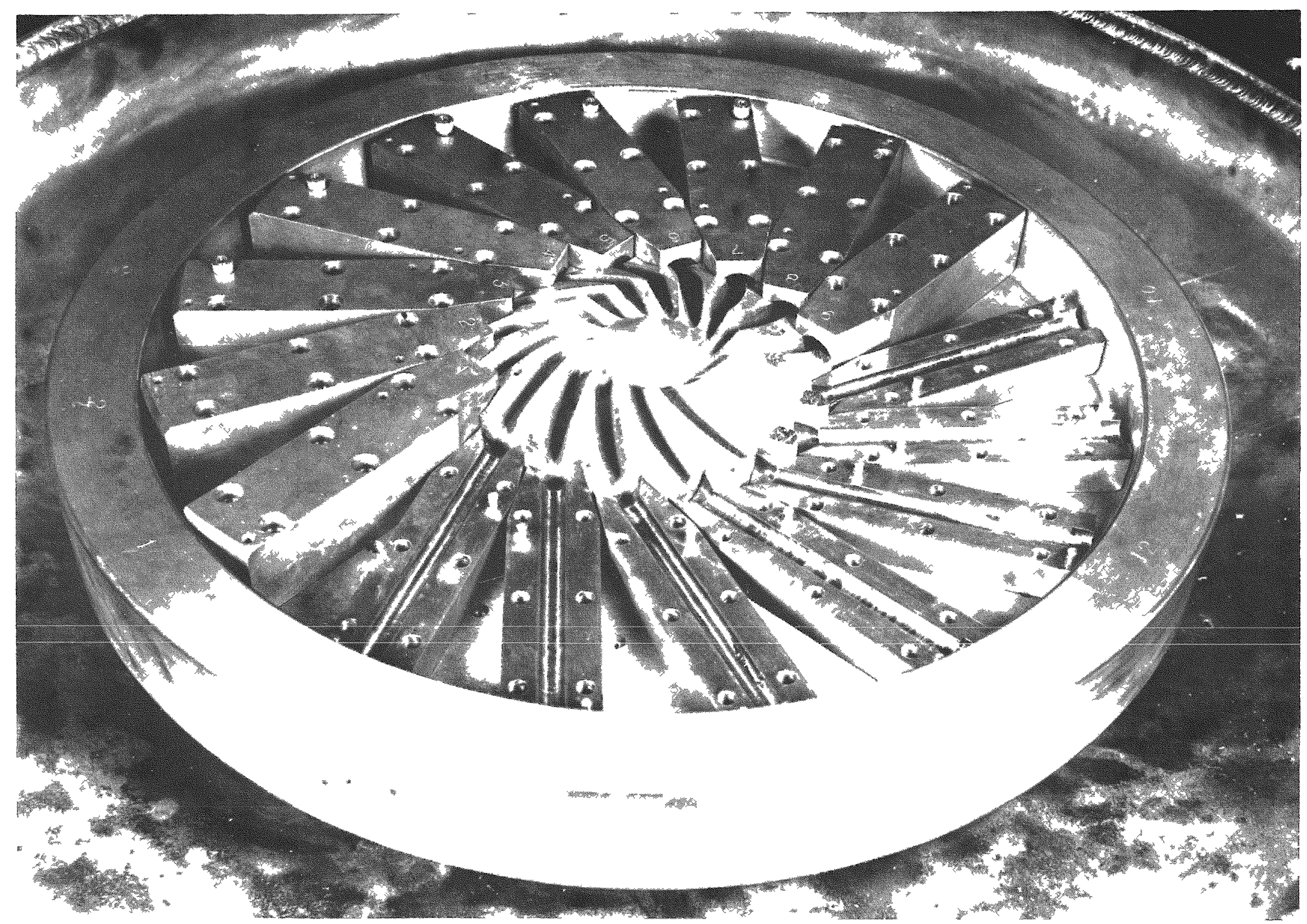


Figure 15. Rotor Table with Molds Ready for Use.






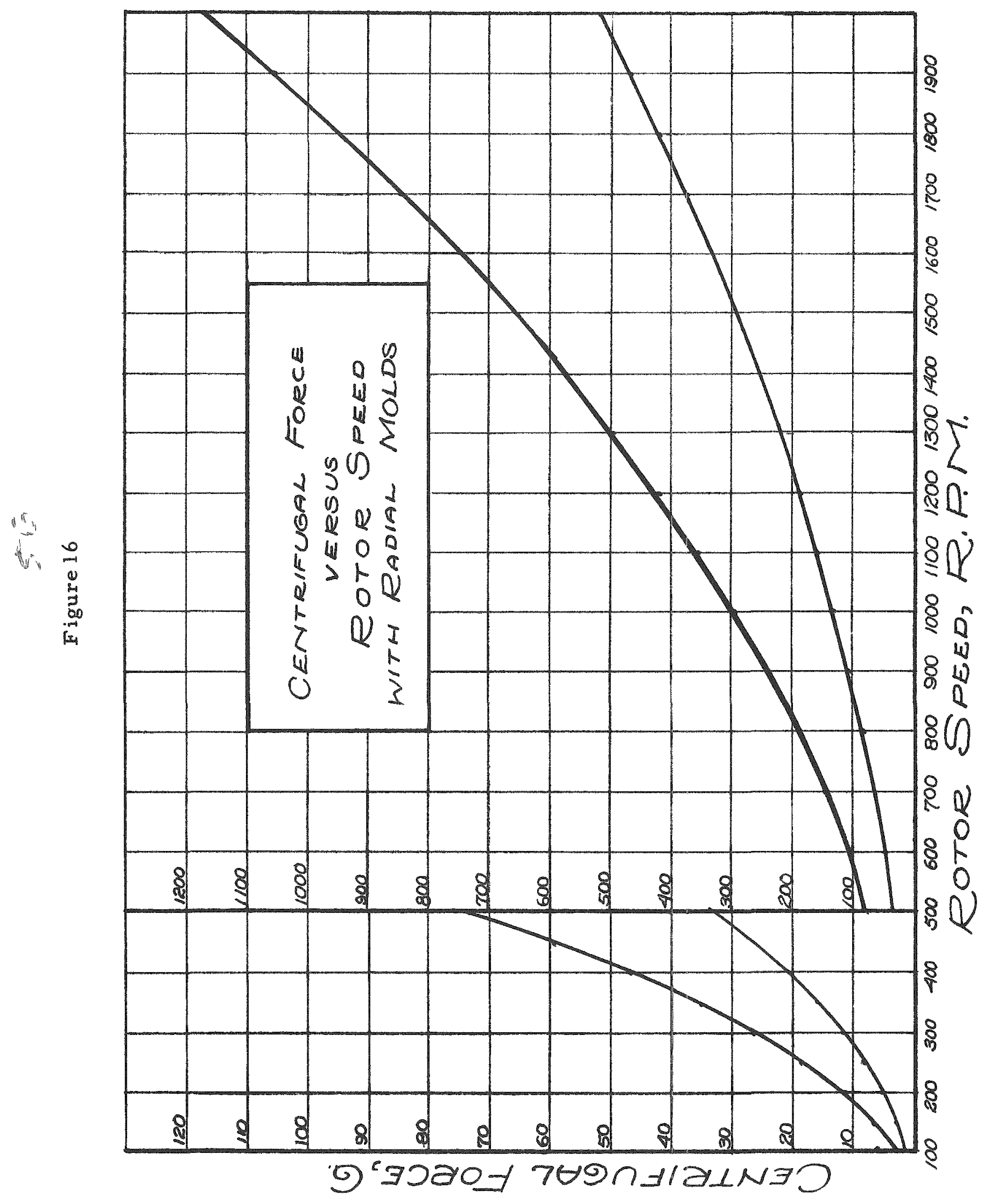




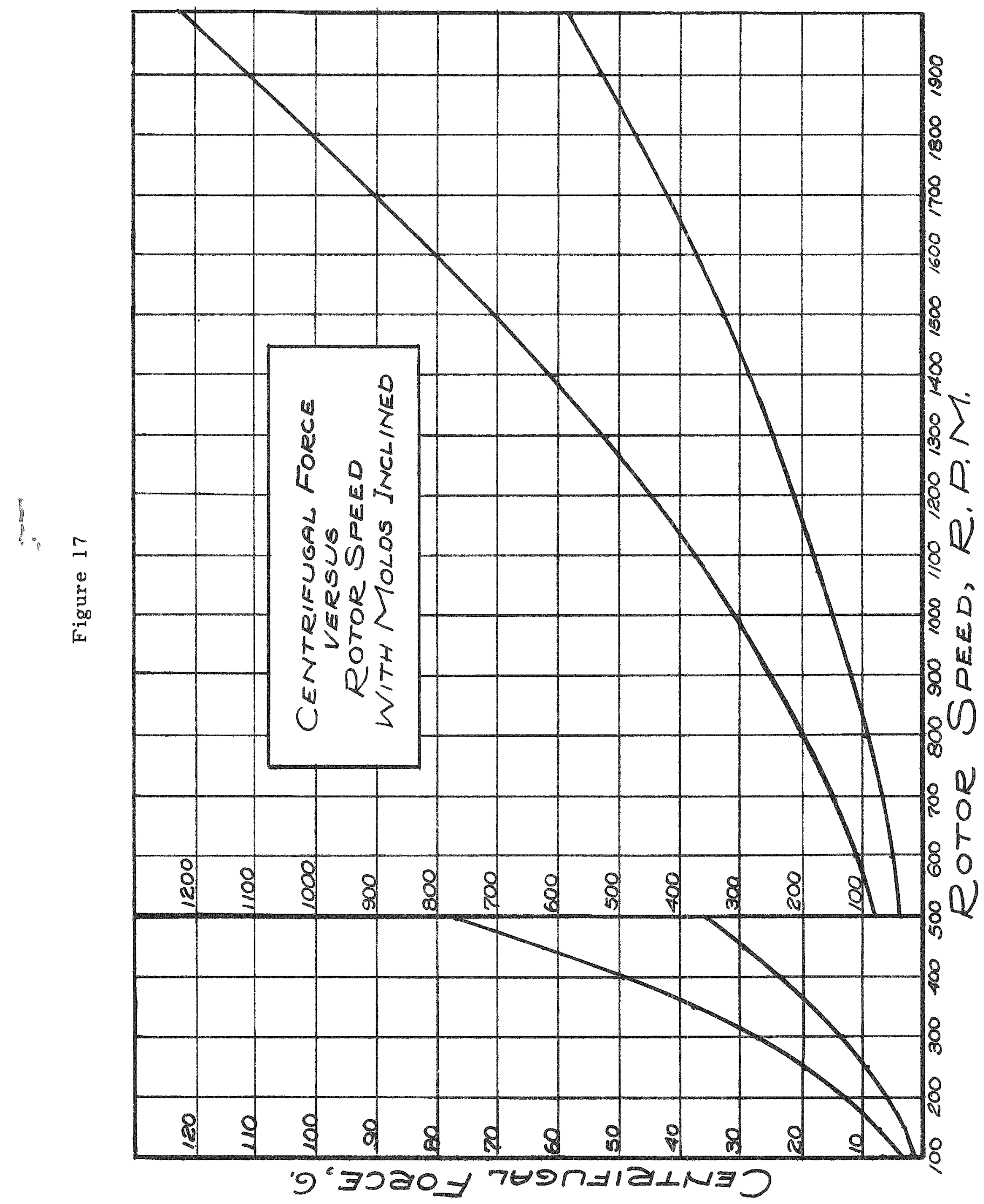


Figure 18. Modified Form of Centrifugal Casting Machine

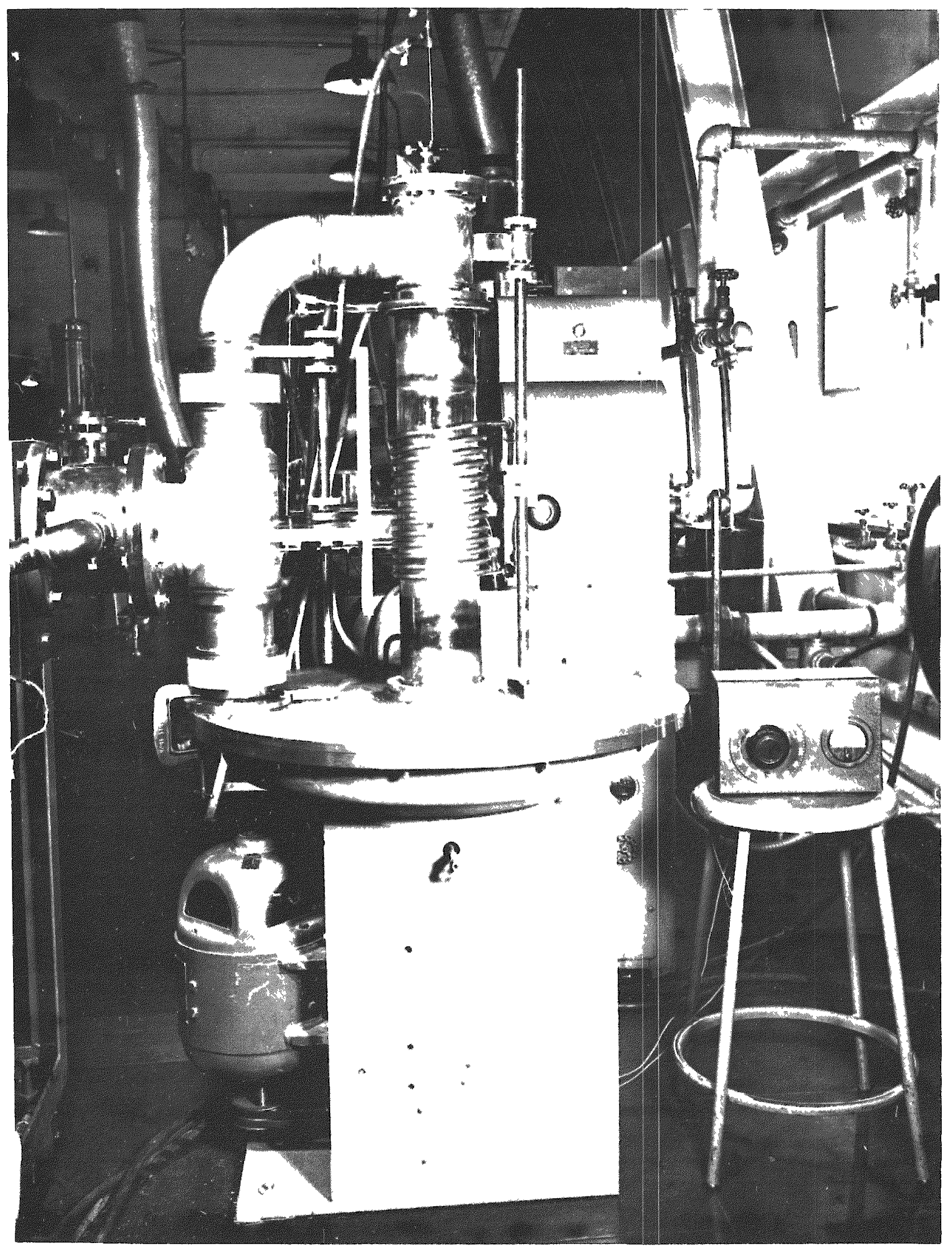

AS 139 
Figure 19. Centrifugal Casting Machine Showing Drive Unit and Vacuum System

$\because \cdots .$.

$\because \cdots$

$\because \cdots$

$\because 0$

:a...

$\therefore .{ }^{\circ}$

$\therefore .$.

$\ldots$

$\because \cdots .$.

$\because \cdots . .$.

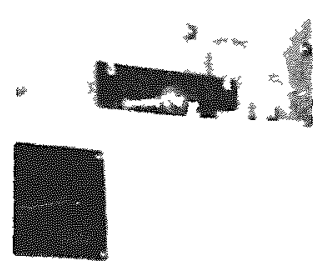

政

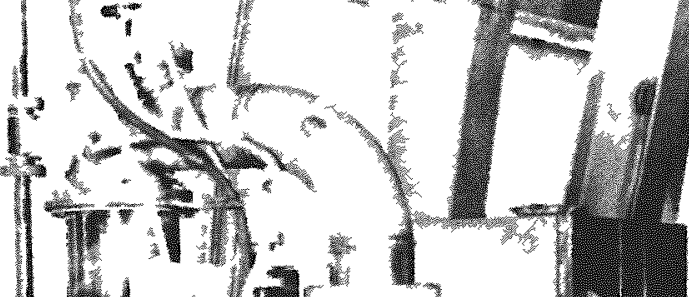

(1)

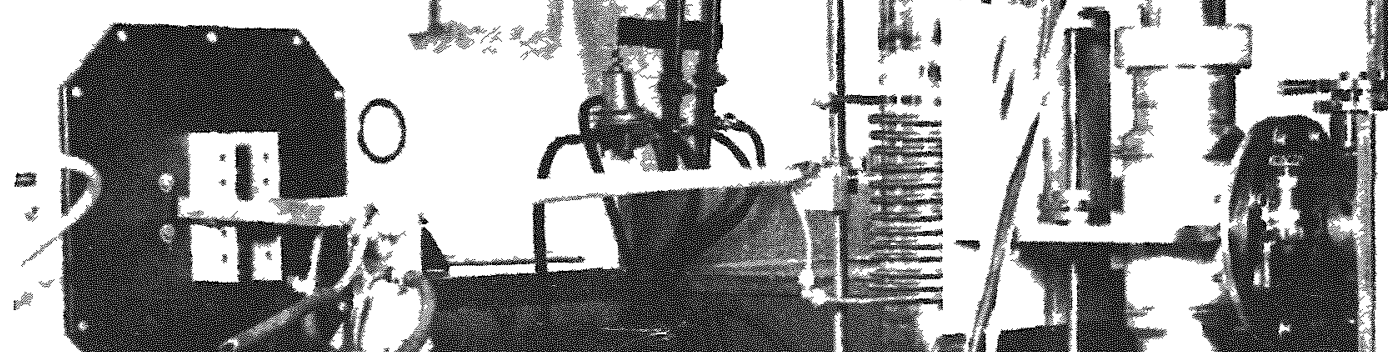

)
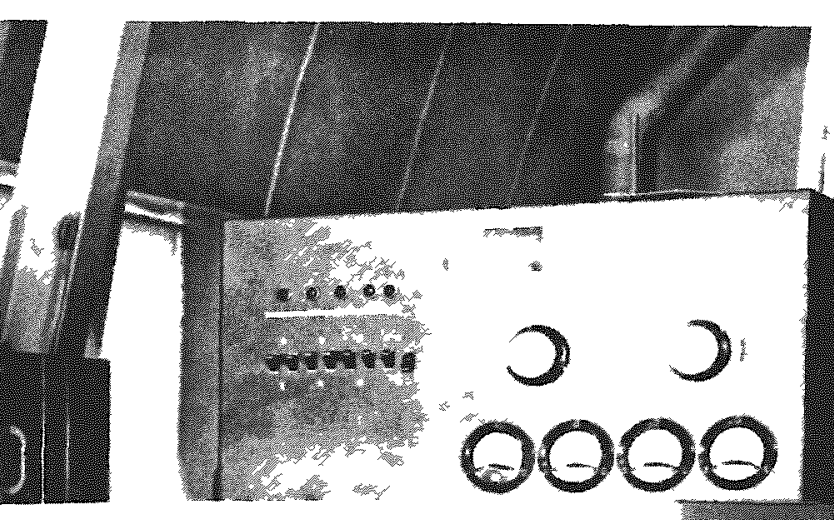

,

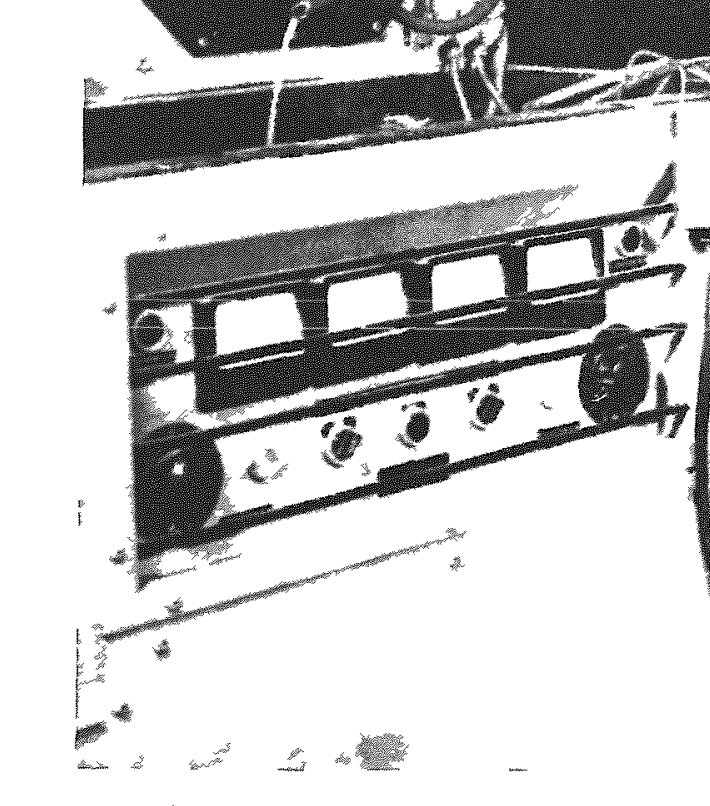

.


AS 143

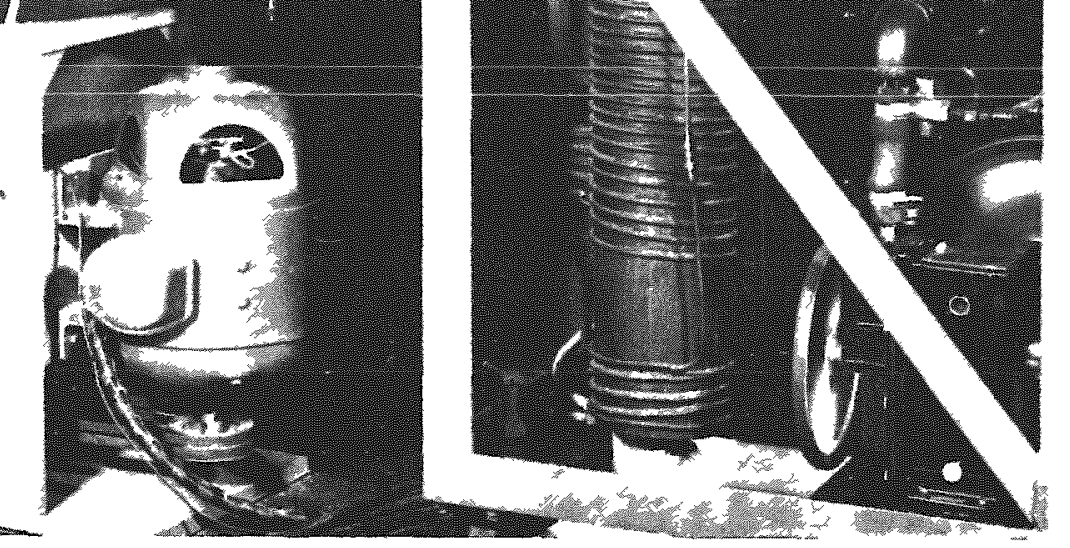




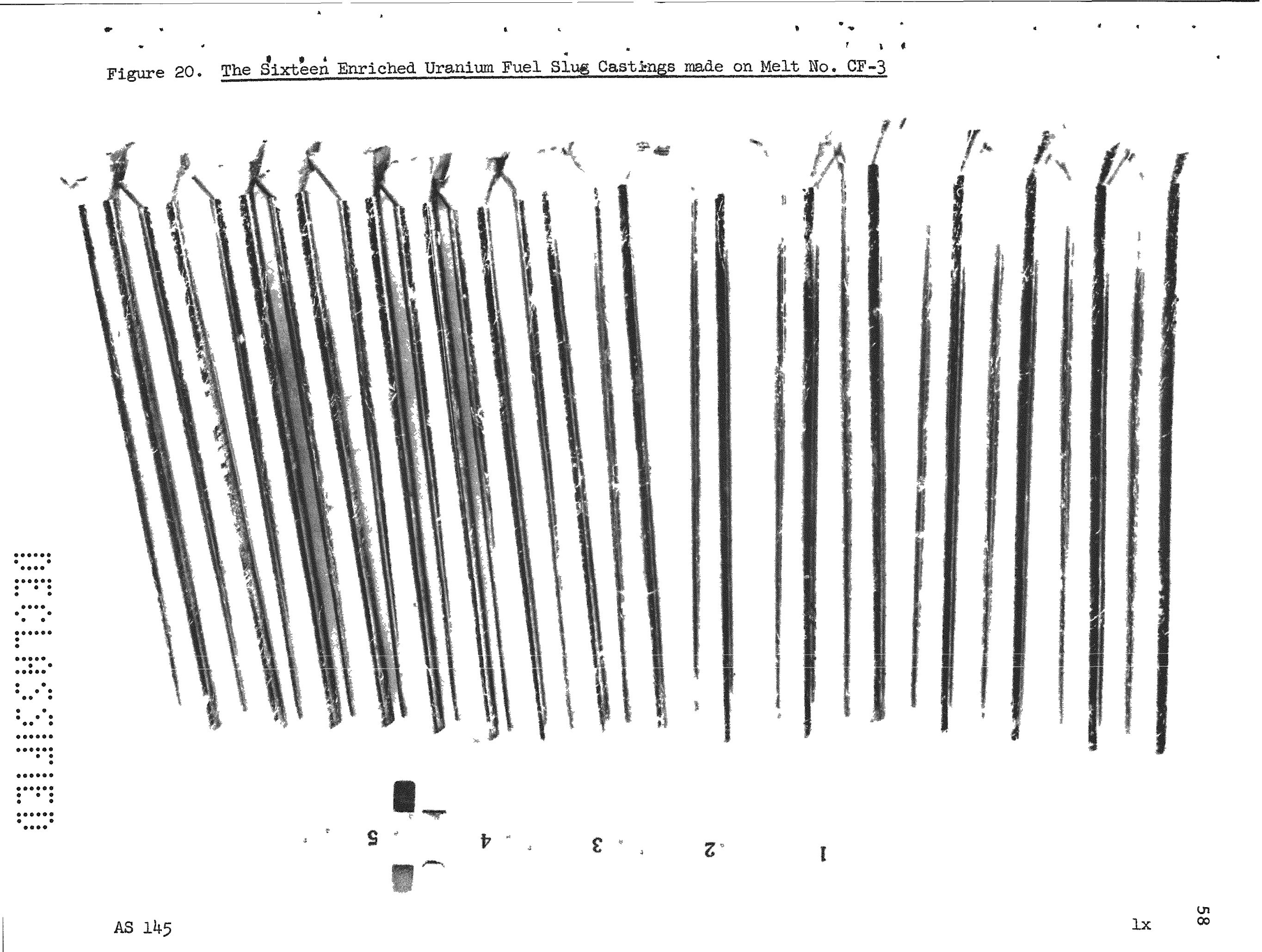


Figure 21. Casting from Melt Number CF-3 Showing Typical Surfaces

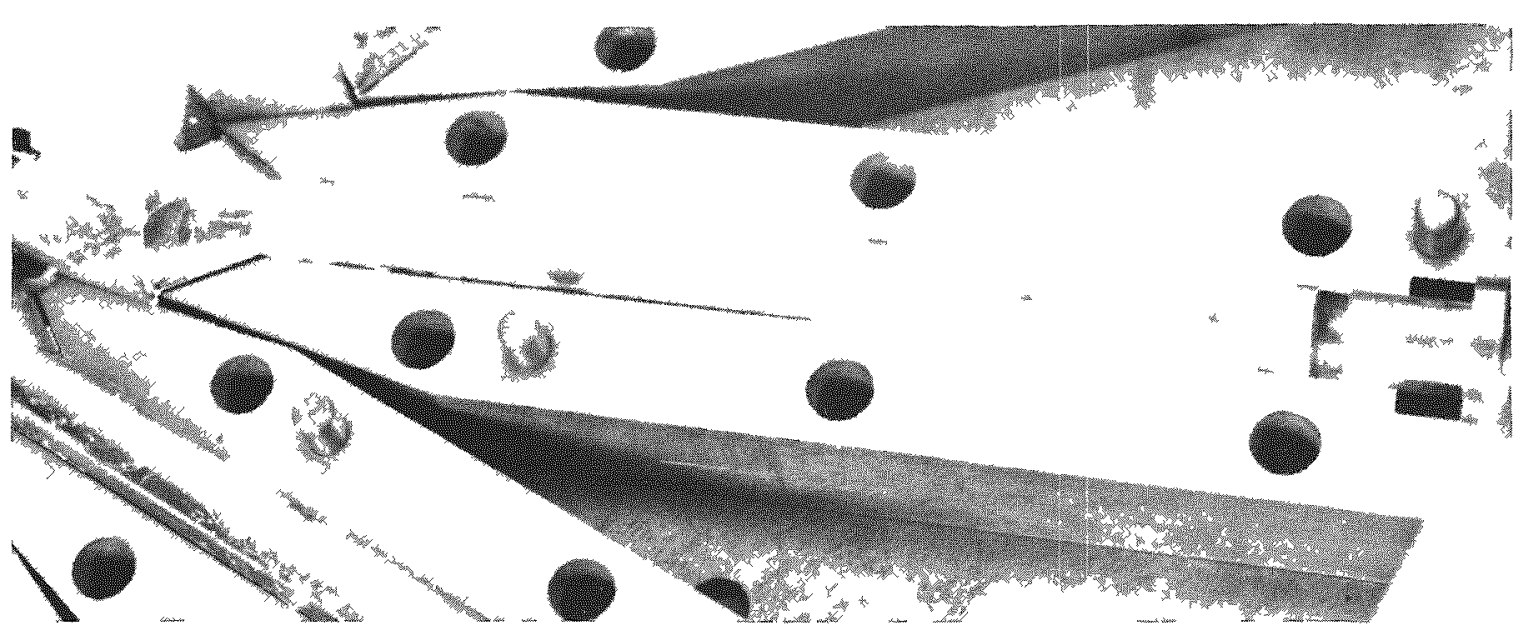

AS 135

$3 / 4 x$ 
Figure 22. Structure of the Centrifugally Cast $2.15 \mathrm{w} / 0$ Zirconium Normal Uranium Alloy

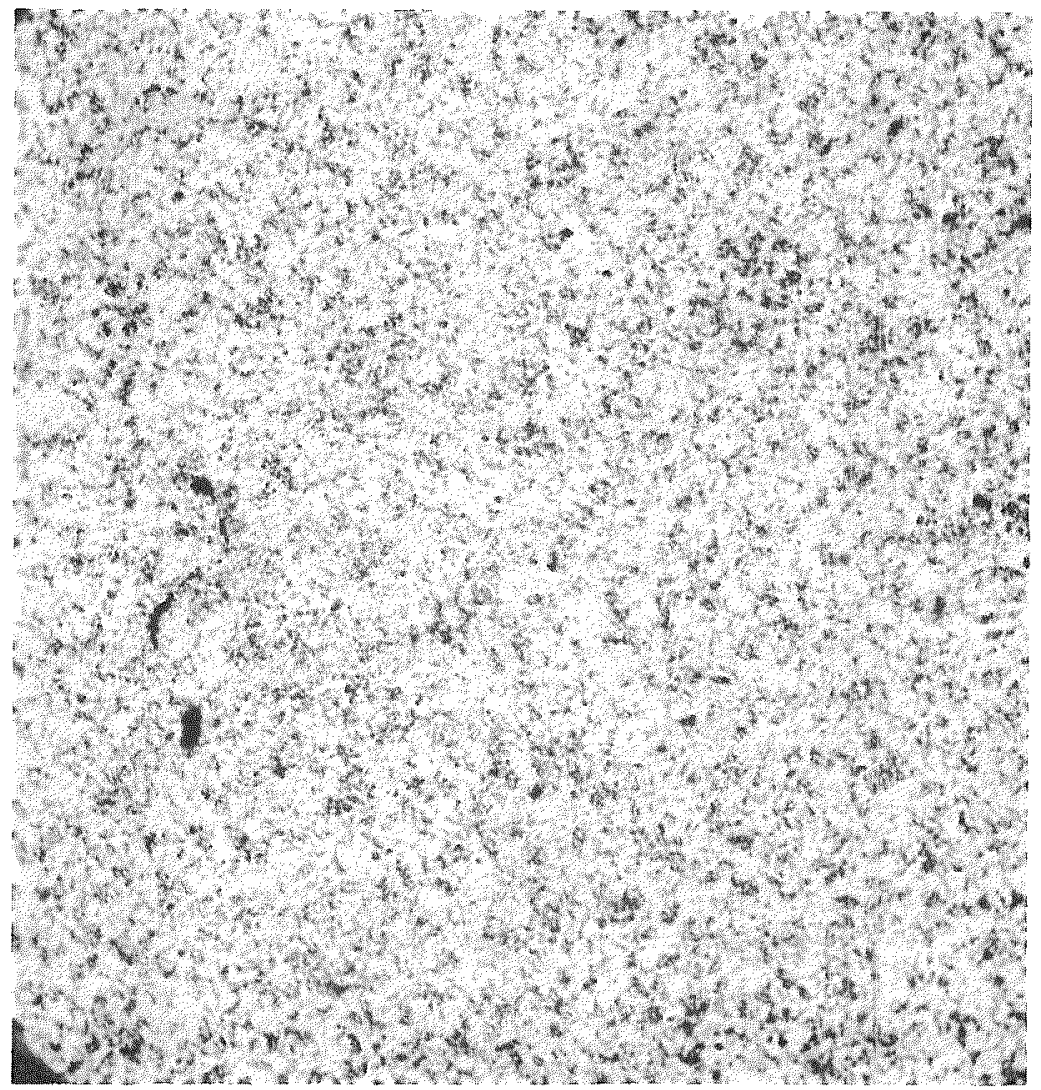

Micro 14518

Electropolished

$100 \mathrm{x}$

\section{Figure 23. The Structure Shown above but at Higher Magnification}

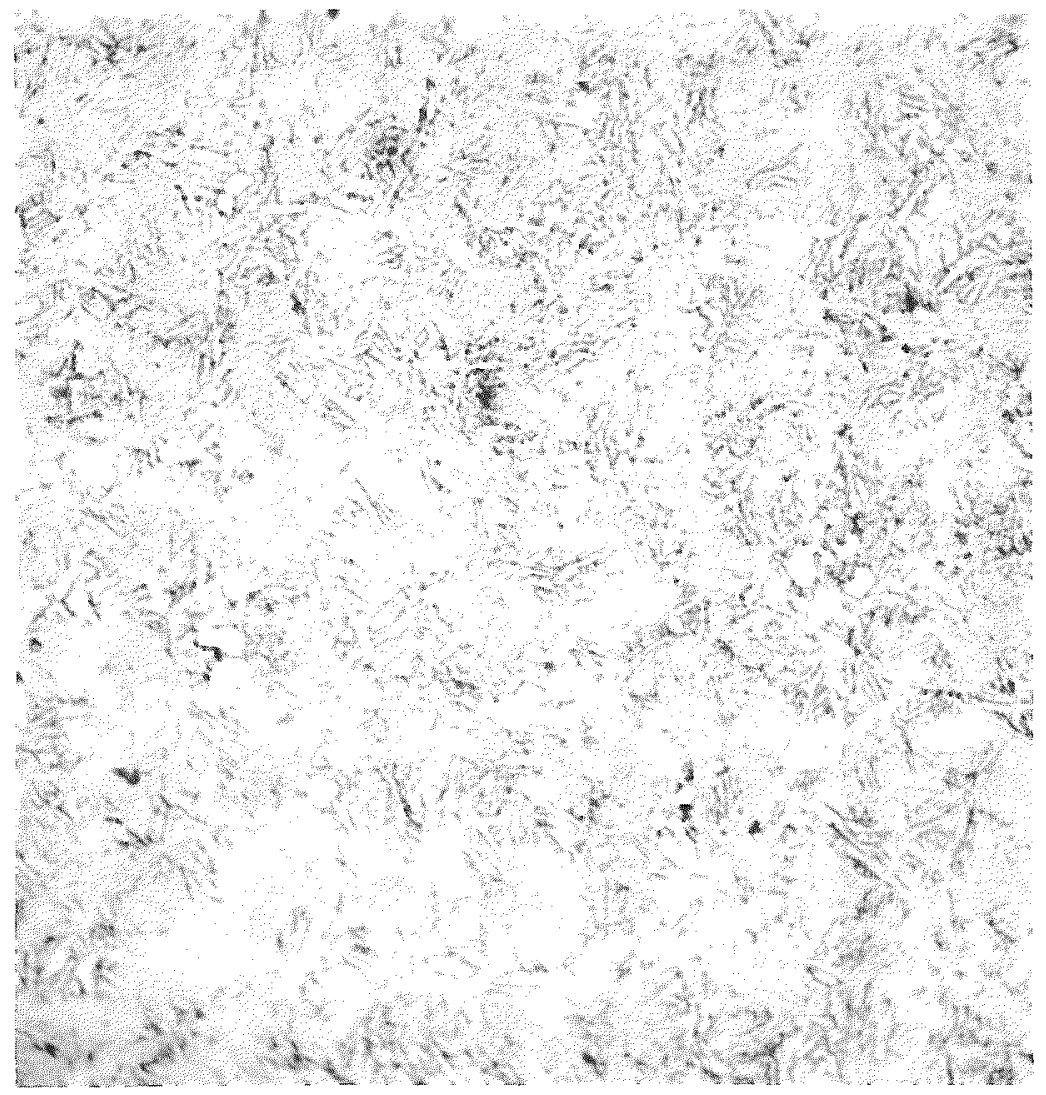


17 1)

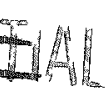

Figure 24. Photomicrogram from Sprue Section of Casting CN 16-5E Showing Inclusion Stringer and Porosity

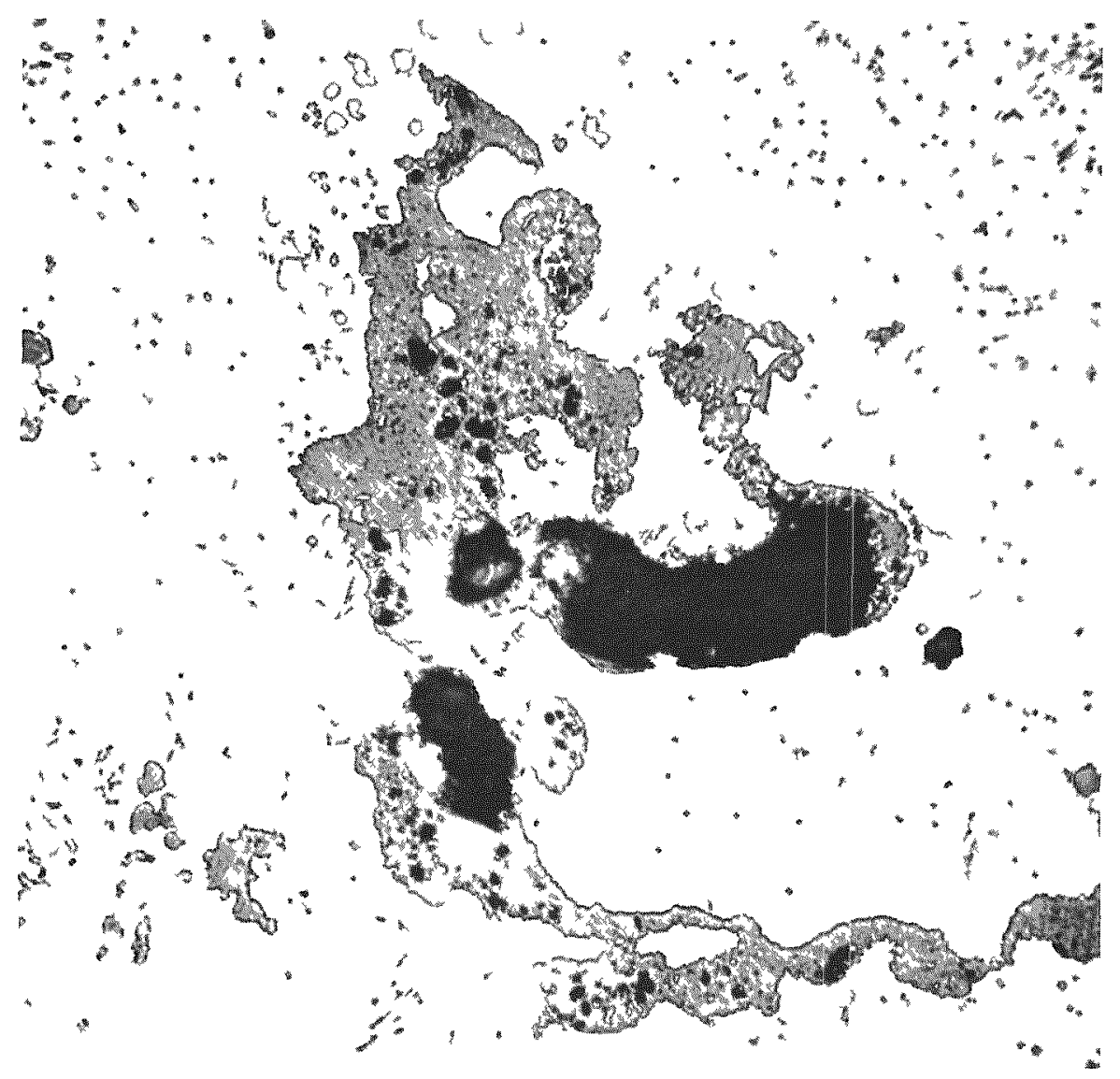

Micro 14504

Electropolished

$500 x$ 